This is a pre-print of an article published in: World Journal of Microbiology and Biotechnology (2019) 35:16. The final authenticated version is available online at: https://doi.org/10.1007/s11274-018-2587-4

\title{
World Journal of Microbiology and Biotechnology Bio-conversion of methane into high profit margin compounds: An innovative, environmentally friendly and cost-effective platform for methane abatement. --Manuscript Draft--
}

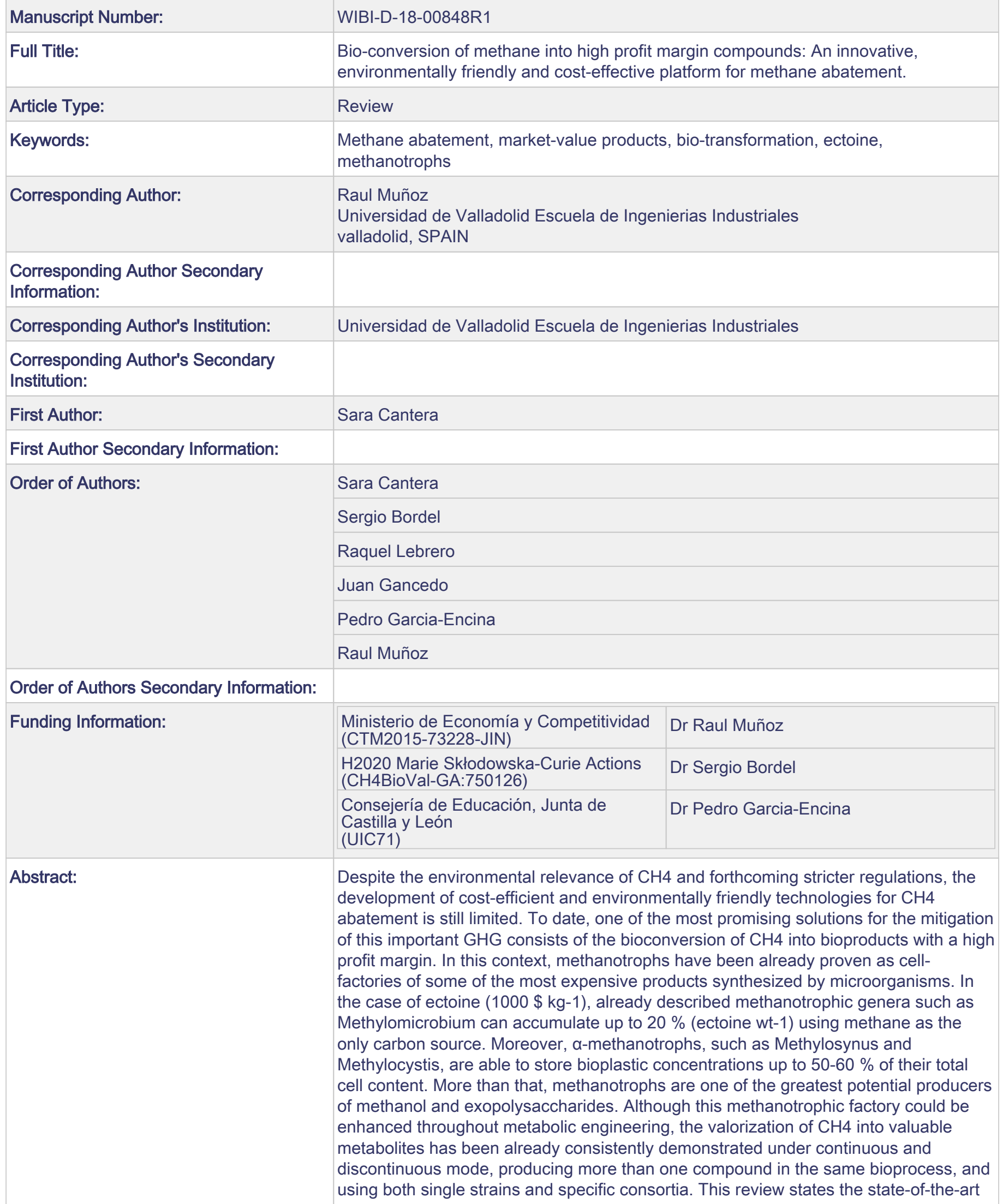


of this innovative biotechnological platform by assessing its potential and current limitations.

Response to Reviewers:
Ms.Ref.No.WIBI-D-18-00848: "Bio-conversion of methane into high profit margin compounds: An innovative, environmentally friendly and cost-effective platform for methane abatement". Submitted for publication to World Journal of Microbiology and Biotechnology.

Dear Editor,

First, we would like to thank you for allowing us to resubmit a revised version of our work to World Journal of Microbiology \& Biotechnology. We have carefully addressed the editor's comments, as well as Reviewer 1 and 3's comments, which has significantly improved the quality of the paper. More specifically:

\section{EDITOR}

The authors acknowledge the commentaries made by the Editor and systematically considered all the recommendations provided.

In addition to the reviewers' comments below, some sections of the manuscript have been identified as being very similar to other published work. These sections must be reworded:

1. The section "Optimization of methanotrophs as cell factories.......". Paragraph 2 , lines 4-12.

The authors have completely modified the section "Methanotrophs as cell factories through metabolic engineering" as requested by the editor and the reviewers (pages 10-11). In this context, the paragraph mentioned by the editor has been deleted and the information included is not similar anymore to other published work.

"Methanotrophs as cell factories through metabolic engineering

Although the availability of sequenced genomes of methanotrophic organisms (www.methanotroph.org) allows a more rigorous investigation of methanotrophic genomics and metabolomics (Campbell et. al. 2011), the limited amount of techniques to deliver genetic material into methanotrophs and the still poor understanding of their metabolism make the genetic manipulation of methanotrophs still scarce.

The first examples of transformation of methanotrophic bacteria were carried out by conjugation with E. coli donors, in particular, the strain S17-1 (Simon et al, 1983). In these studies, conjugation was performed in plates in which the methanotrophic growth medium was supplemented with nutrients suitable for the donor strain and incubated in a methane-containing atmosphere. The selection of methanotrophs was carried out by using naladixic acid or rifamycin, as many methanotrophs are resistant to these antibiotics. However, this method was slow and presented a low efficiency. More recent research has successfully used electroporation to deliver DNA in methanotrophs such as Methylocystis sp. SC2 (Baani \& Liesack, 2008) and M. silvestris BL2 (Crombie \& Murrell, 2011). In fact, there is already a high variety of replicating vectors that can be used to express heterologous genes in methanotrophs, some of the most used vector families being IncP, pBBR and IncQ. Moreover, gene deletions or insertions into the chromosome can be carried out using homologous recombination with large flanking regions (of at least 500 bp in each flank). A popular tool that has gained importance these days to improve the production of valuable metabolites is the rational design of metabolic engineering strategies called Genome Scale Metabolic Models (GSMMs) (Liu et al. 2010). These models can be used to predict the outcome of genetic manipulations, saving time and experimental resources in the process of strain optimization. There are currently a wide number of tools for the automated reconstruction of GSMMs from genomic sequences, such as the SEED server (Henry et al. 2010) and the RAVEN toolbox (Agren et al. 2013). GSMMs have been already developed for two methanotrophic bacteria, M. buryatense and M. alcaliphilum 20Z. A model of M. buryatense was first published in 2015 (Torre et al. 2015), which represented the first GSMM published for a methanotroph and contained a total of 841 metabolic reactions. This model was used to elucidate the electron carrier that reduces oxygen to water during methane oxidation into methanol. Although, three different theories to explain this step of methane metabolic pathway had been postulated hitherto, the redox-arm mode, the direct coupling mode and the uphill electron transfer (Fig. 4), the GSMM of M. buryatense allowed to corroborate the direct coupling mode as the most plausible mechanism due to the comparison of biomass yields and $\mathrm{CH} 4: \mathrm{O} 2$ consumption ratios. Similarly, a model of M. alcaliphilum $20 Z$ published in 2018 (Akberdin et al. 2018) confirmed the direct coupling mode as the 
methane oxidation mechanism. Moreover, this model was subsequently used to find knockout targets for the optimization of the production of 2,3-butanediol (Nguyen et al. 2018). These knockout targets were found by modeling the effects of a knockout using MOMA (Minimization Of Metabolic Adjustment) to simulate the perturbation caused by a gene knockout on the distribution of metabolic fluxes, and the algorithm OptGene (Patil et al. 2005) to find sets of knockouts leading to increased 2,3-butanediol productivities. The implementation of a triple knockout of the genes MDH, LDH and ACKr, resulted in a $64 \%$ increase of the production of 2,3-butanediol (Nguyen et al., 2018). “

2. The section "Extracellular polysaccharides......". Paragraph 1, lines 1-6. The authors have modified the section "Extracellular polysaccharides and secondary methane-driven bioproducts" (Paragraph 1, lines 1-6) in accordance to the editor's suggestion (pages 8-9):

"Microbial extracellular polysaccharides (EPS) constitute a wide diversity of molecules conformed by homopolysaccharides or heteropolysaccharides combined with proteins and lipids. Bacteria secret them to the surrounding environment for different purposes such as adherence of cells to surfaces, migration, protection from predators, toxics or extreme conditions. Microbial EPS are nowadays actively used in various industries such as the food, pharmaceutical, oil and textile industry, due to their colloidal and adhesive properties, and their beneficial effects on liquid rheology (Nwodo et al. 2012)."

\section{REVIEWER 1}

The authors acknowledge the feedback from Reviewer 1 and systematically considered all recommendations provided. Thus, the description and interpretation of the results obtained have been significantly improved in order to generate a better understanding of the experimentation conducted in this paper.

General comments:

The manuscript submitted by Cantera S. et al. is a review and focuses on methanebased bio-transformations. Overall the study is divided into two main parts. In the first part the current state of technologies of the microbial production of ectoine and hydroxyectoine, PHAs and PHBs as well as extracellular polysaccharides and secondary methane-driven bioproducts are summarized and potential strategies to improve the underlying microbial metabolism are discussed. In the second part, bioprocess engineering solutions are shown and pros and cons of bioreactors used today are discussed.

1. The work is written in a too general way and touches the topics only at the surface. Descriptions and explanations throughout the manuscript are very difficult to understand and as in case of the GSMM mostly textbook knowledge.

The authors agree with Reviewer 1 in the sense that the text is sometimes too general and difficult to understand in some sections (i.e Methanotrophs as cell factories through metabolic engineering). This was mainly due to the space limitation and the attempt of the authors to encompass the all recent discoveries in the field from an engineering, biotechnological and molecular biology point of view. However, the result seemed to be a vague and too general description of the current state of the art of methane bioconversion technologies. In this context, the section "Bioreactor configuration..." has been removed from the revised version of this manuscript. Moreover, the section "Methanotrophs as cell factories through metabolic engineering" has been entirely rewritten and more updated information has been included in this specific section to make it easier to follow and enhance its impact. Additionally, a more exhaustive description of the four most promising bioproducts produced from methane oxidation has been included in this revised version. In this context, methanol has been included in this review and the information supported has been complemented with new figures (methanol and PHA production) and a table that compiles the main methanotrophic bacteria involved in the production of high added value compounds from methane.

2. The work is too heterogeneous. The two parts (products / bioreactors) are presented without context and it is not clear to the reader why the bioreactors part was included. Concentrating on only one part would give the authors the opportunity to explain the topics more comprehensibly and discuss them with the required scientific quality. The authors agree with Reviewer 1 on the limited details provided in the original 
manuscript for the envisaged methane biotransformation processes. This lack of explanation was due to the limited space available. However, in the revised version of this manuscript, the bioreactor part has been deleted and the manuscript has been entirely focused on the biotransformation of methane into bioproducts with a high market value. Hence, novel information and more detailed descriptions about the metabolic pathways, the microbes used and the high market valuable compounds produced have been included in the revised version of this manuscript. In addition, new bioproducts such as methanol, a new table with the microorganisms involved in these processes, as well as two new figures to make more visual the production of PHAs and methanol have been incorporated to the revised version of this manuscript.

3. After reading the manuscript it is not clear why this study should be published. The major goal of the review, the current state of and what is limiting methane-based bioconversions are not well or not described.

The current state of the art and the current limitations of these biotechnologies have been more exhaustively described in this revised manuscript, throughout the addition of new sections referring to different compounds, a more detailed explanation of the current methanotrophic bacteria producing secondary metabolites with a high profit margin and including a new table and figures.

4. The reference list is by far not complete, which in case of a review is a minimum requirement (e.g. (just from a quick survey) Environ.Sci.Technol., 2015, 49,4001-4018; J.Environ.Manage., 2016,182, 160; Eng.LifeSc., 2010, 10, 87.102, ...)

The authors apologize for these mistakes and have carefully corrected the reference section in the revised version of this manuscript.

5. The choice of products appears to be selective. Why did the authors left out other prominent and valuable products such as methanol.

The authors apologize for not including this product, which is gaining importance and whose production from methane is attracting an increasing attention worldwide.

Therefore, a new section called "Methanol production from methane" has been included in the revised version of this manuscript (pages 6 to 8 ).

\section{REVIEWER 3}

This review gave a broad and general outline of how to use methane to produce other valuable products. Specific comments are listed below:

1) Abstract The authors spent most space talking about what an introduction usually does. Please be more specific about potential products to be produced from methane and a variety of microbes to be used as well as fermentation processes involved.

The authors agree with Reviewer 3 on the lack of specific information included in the original abstract about the subject that was further described in the manuscript. Thus, a more detailed explanation along with new information about the potential compounds that can be produced from methane, and the organisms involved in the process, were added to the abstract of this revised manuscript.

"Despite the environmental relevance of $\mathrm{CH} 4$ and forthcoming stricter regulations, the development of cost-efficient and environmentally friendly technologies for $\mathrm{CH} 4$ abatement is still limited. To date, one of the most promising solutions for the mitigation of this important GHG consists of the bioconversion of $\mathrm{CH} 4$ into bioproducts with a high profit margin. In this context, methanotrophs have been already proven as cellfactories of some of the most expensive products synthesized by microorganisms. In the case of ectoine (1000 \$ kg-1), already described methanotrophic genera such as Methylomicrobium can accumulate up to $20 \%$ (ectoine wt-1) using methane as the only carbon source. Moreover, a-methanotrophs, such as Methylosynus and Methylocystis, are able to store bioplastic concentrations up to $50-60 \%$ of their total cell content. More than that, methanotrophs are one of the greatest potential producers of methanol and exopolysaccharides. Although this methanotrophic factory could be enhanced throughout metabolic engineering, the valorization of $\mathrm{CH} 4$ into valuable metabolites has been already consistently demonstrated under continuous and discontinuous mode, producing more than one compound in the same bioprocess, and using both single strains and specific consortia. This review states the state-of-the-art of this innovative biotechnological platform by assessing its potential and current limitations." 
2)Please provide a Table of microbes used and products produced with references listed.

The authors agree with Reviewer 3 on the fact that the addition of a table compiling the microbes used and substrates produced would enhance the quality of this review. In this regard, Table 1 has been included in order to provide this information.

Moreover, the references listed on the table have been added to the reference section of the revised manuscript.

3)Page 4, please cite a reference for $230+20 \mathrm{mg}$ ectoine $\mathrm{g}$ biomass.

The authors apologize for this error and included the reference requested (Khmelenina et al. 2000) in the revised manuscript (this reference was already part of the reference section) (page 4):

"M. alcaliphilum has been shown to reach intracellular ectoine concentrations up to 230 $\pm 20 \mathrm{mg}$ ectoine $\mathrm{g}$ biomass -1 using $\mathrm{CH} 4$ as the only carbon and energy source (Khmelenina et al. 2000)".

4)Page 6, Please explain the RUMP-pathway

The authors agree with Reviewer 3 on the fact that the RUMP-pathway, as well as the serine pathway, were not well explained in the original manuscript. The information requested by Reviewer 3 was included in this revised version of the manuscript (current page 5).

"Methanotrophs are divided into two different groups based on their carbon assimilation pathway:

1.a-proteobacterial methanotrophs, which utilize the serine cycle for formaldehyde assimilation. In this cycle, methane is converted to formate, which itself is converted to methylene tetrahydrofolate. Methylene H4F condenses with glycine to generate serine. 2. The gamma-proteobacterial methanotrophs, which use the ribulose monophosphate cycle where formaldehyde is condensed with ribulose monophosphate to create a hexulose phosphate, which itself is converted to fructose-6-phosphate (Anthony, 2011)."

The following reference has been included to the references section:

Anthony C. (2011). How half a century of research was required to understand bacterial growth on $\mathrm{C} 1$ and $\mathrm{C} 2$ compounds; the story of the serine cycle and the ethylmalonyl-CoA pathway. Science progress 94, 109-137.

5)Page 8, Please explain in more details about the method used for metabolic engineering, which pathway was redirected and what available techniques for molecular cloning can be applied?

The information requested by Reviewer 3 has been added to the revised version of this manuscript (page 11):

"GSMMs have been already developed for two methanotrophic bacteria, M. buryatense and M. alcaliphilum 20Z. A model of M. buryatense was first published in 2015 (Torre et al. 2015), which represented the first GSMM published for a methanotroph and contained a total of 841 metabolic reactions. This model was used to elucidate the electron carrier that reduces oxygen to water during methane oxidation into methanol. Although, three different theories to explain this step of methane metabolic pathway had been postulated hitherto, the redox-arm mode, the direct coupling mode and the uphill electron transfer (Fig. 4), the GSMM of M. buryatense allowed to corroborate the direct coupling mode as the most plausible mechanism due to the comparison of biomass yields and $\mathrm{CH} 4: \mathrm{O} 2$ consumption ratios. Similarly, a model of M. alcaliphilum $20 Z$ published in 2018 (Akberdin et al. 2018) confirmed the direct coupling mode as the methane oxidation mechanism. Moreover, this model was subsequently used to find knockout targets for the optimization of the production of 2,3-butanediol (Nguyen et al. 2018). These knockout targets were found by modeling the effects of a knockout using MOMA (Minimization Of Metabolic Adjustment) to simulate the perturbation caused by a gene knockout on the distribution of metabolic fluxes, and the algorithm OptGene (Patil et al. 2005) to find sets of knockouts leading to increased 2,3-butanediol productivities. The implementation of a triple knockout of the genes MDH, LDH and ACKr, resulted in a $64 \%$ increase of the production of 2,3-butanediol (Nguyen et al., 2018)."

The following references have been included in the revised version of these 
manuscript:

Torre A, Metivier A, Chu F, et al. (2015) Genome-scale metabolic reconstructions and theoretical investigation of methane conversion in Methylomicrobium buryatense strain 5G(B1). Microb Cell Fact. 14:188. doi: 10.1186/s12934-015-0377-3.

Nguyen AD, Hwang IY, Lee OK, et al. (2018) Systematic metabolic engineering of Methylomicrobium alcaliphilum $20 \mathrm{Z}$ for 2,3-butanediol production from methane. Metab Eng. 47:323-333. doi: 10.1016/j.ymben.2018.04.010.

6)Page 8, a direct gene-protein-reaction does not apply in metabolic models, please clarify

A direct gene-protein-reaction is a well-known feature of Genome Scale Metabolic models, so we believe that the reviewer claims that "a direct gene-protein-reaction connection" does not apply because some word in this paragraph made the statement confusing. In this regard, this information has been removed from the manuscript to avoid further misunderstanding.

7)Fig. 1. Please describe what enzymes/proteins of these genes ectA, ectB, ect $C$ and asK encode for? and also explain how ectoine is accumulated.

The authors apologize for this error and included a more detailed explanation about ectoine accumulation and about the enzymes involved in the ectoine pathway.

Moreover, the name of the enzymes involved in ectoine production has been included in figure 1 legend (current page 3):

"In response to a high salinity of the growth medium, these methanotrophic bacteria accumulate ectoine as the major osmoprotective compound inside the cytoplasm without disturbing the cell's metabolism (including nucleic acid and lipid metabolism) even at high molar cytoplasmic concentrations. The ectoine biosynthesis pathway in M. alcaliphilum $20 Z$ has been deeply studied (Mustakhimov et al. 2009). It is similar to the pathway employed by halophilic/halotolerant heterotrophs and involves three specific enzymes: diaminobutyric acid (DABA) aminotransferase (EctB), DABA acetyltransferase (EctA), and ectoine synthase (EctC) (encoded by the conserved gene cluster, ectABC), which together catalyze the conversion of the precursor aspartate into ectoine, plus an additional gene of aspartokinase (Ask) conforming an ectABC-ask cluster (Fig. 1) (Reshetnikov et al. 2011)."

This reference has been included in the revised version of this manuscript: Mustakhimov II, Reshetnikov AS, Glukhov AS, et al. (2009) Identification and characterization of EctR1, a new transcriptional regulator of the ectoine biosynthesis genes in the halotolerant methanotroph Methylomicrobium alcaliphilum 20Z. J Bacteriol.192(2):410-7.

"Fig. 1. Accumulation of ectoine in M. alcaliphilum 20Z, pathway for the synthesis of ectoine. Adapted from Pastor et al. (2010). ectA encodes for the protein DABA acetyltransferase (EctA), ectB for diaminobutyric acid (DABA) aminotransferase (EctB), ectC for ectoine synthase (EctC) and ask for aspartokinase (Ask)."

We hope that these modifications will comply with the requests of World Journal of Microbiology \& Biotechnology. Please do not hesitate to contact us at your convenience if you need further information.

Sara Cantera \& Raúl Muñoz 


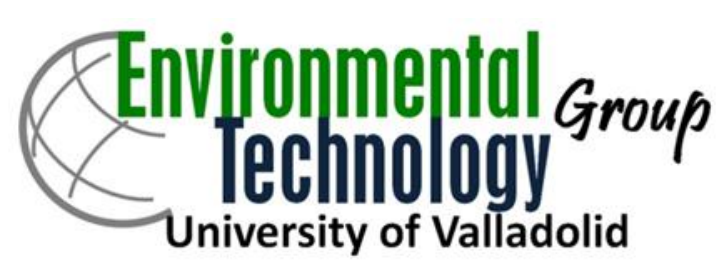

Ian S. Maddox, PhD

Associate Editor

World Journal of Microbiol. and Biotech.

\begin{abstract}
Ms.Ref.No.WIBI-D-18-00848: "Bio-conversion of methane into high profit margin compounds: An innovative, environmentally friendly and cost-effective platform for methane abatement”. Submitted for publication to World Journal of Microbiology and Biotechnology.
\end{abstract}

Dear Editor,

First, we would like to thank you for allowing us to resubmit a revised version of our work to World Journal of Microbiology \& Biotechnology. We have carefully addressed the editor's comments, as well as Reviewer 1 and 3's comments, which has significantly improved the quality of the paper. More specifically:

\title{
EDITOR
}

The authors acknowledge the commentaries made by the Editor and systematically considered all the recommendations provided.

In addition to the reviewers' comments below, some sections of the manuscript have been identified as being very similar to other published work. These sections must be reworded: 1. The section "Optimization of methanotrophs as cell factories.......". Paragraph 2, lines 4-12.

The authors have completely modified the section "Methanotrophs as cell factories through metabolic engineering" as requested by the editor and the reviewers (pages 10-11). In this context, the paragraph mentioned by the editor has been deleted and the information included is not similar anymore to other published work. 


\section{"Methanotrophs as cell factories through metabolic engineering}

Although the availability of sequenced genomes of methanotrophic organisms (www.methanotroph.org) allows a more rigorous investigation of methanotrophic genomics and metabolomics (Campbell et. al. 2011), the limited amount of techniques to deliver genetic material into methanotrophs and the still poor understanding of their metabolism make the genetic manipulation of methanotrophs still scarce.

The first examples of transformation of methanotrophic bacteria were carried out by conjugation with $E$. coli donors, in particular, the strain S17-1 (Simon et al, 1983). In these studies, conjugation was performed in plates in which the methanotrophic growth medium was supplemented with nutrients suitable for the donor strain and incubated in a methanecontaining atmosphere. The selection of methanotrophs was carried out by using naladixic acid or rifamycin, as many methanotrophs are resistant to these antibiotics. However, this method was slow and presented a low efficiency. More recent research has successfully used electroporation to deliver DNA in methanotrophs such as Methylocystis sp. SC2 (Baani \& Liesack, 2008) and M. silvestris BL2 (Crombie \& Murrell, 2011). In fact, there is already a high variety of replicating vectors that can be used to express heterologous genes in methanotrophs, some of the most used vector families being IncP, pBBR and IncQ. Moreover, gene deletions or insertions into the chromosome can be carried out using homologous recombination with large flanking regions (of at least $500 \mathrm{bp}$ in each flank).

A popular tool that has gained importance these days to improve the production of valuable metabolites is the rational design of metabolic engineering strategies called Genome Scale Metabolic Models (GSMMs) (Liu et al. 2010). These models can be used to predict the outcome of genetic manipulations, saving time and experimental resources in the process of strain optimization. There are currently a wide number of tools for the automated reconstruction of GSMMs from genomic sequences, such as the SEED server (Henry et al. 2010) and the RAVEN toolbox (Agren et al. 2013).

GSMMs have been already developed for two methanotrophic bacteria, M. buryatense and M. alcaliphilum 20Z. A model of M. buryatense was first published in 2015 (Torre et al. 2015), which represented the first GSMM published for a methanotroph and contained a total of 841 metabolic reactions. This model was used to elucidate the electron carrier that reduces 
oxygen to water during methane oxidation into methanol. Although, three different theories to explain this step of methane metabolic pathway had been postulated hitherto, the redoxarm mode, the direct coupling mode and the uphill electron transfer (Fig. 4), the GSMM of $M$. buryatense allowed to corroborate the direct coupling mode as the most plausible mechanism due to the comparison of biomass yields and $\mathrm{CH}_{4}: \mathrm{O}_{2}$ consumption ratios. Similarly, a model of M. alcaliphilum $20 \mathrm{Z}$ published in 2018 (Akberdin et al. 2018) confirmed the direct coupling mode as the methane oxidation mechanism. Moreover, this model was subsequently used to find knockout targets for the optimization of the production of 2,3-butanediol (Nguyen et al. 2018). These knockout targets were found by modeling the effects of a knockout using MOMA (Minimization Of Metabolic Adjustment) to simulate the perturbation caused by a gene knockout on the distribution of metabolic fluxes, and the algorithm OptGene (Patil et al. 2005) to find sets of knockouts leading to increased 2,3butanediol productivities. The implementation of a triple knockout of the genes MDH, LDH and ACKr, resulted in a 64\% increase of the production of 2,3-butanediol (Nguyen et al., 2018). “

\section{The section "Extracellular polysaccharides......". Paragraph 1, lines 1-6.}

The authors have modified the section "Extracellular polysaccharides and secondary methane-driven bioproducts" (Paragraph 1, lines 1-6) in accordance to the editor's suggestion (pages 8-9):

${ }^{6}$ Microbial extracellular polysaccharides (EPS) constitute a wide diversity of molecules conformed by homopolysaccharides or heteropolysaccharides combined with proteins and lipids. Bacteria secret them to the surrounding environment for different purposes such as adherence of cells to surfaces, migration, protection from predators, toxics or extreme conditions. Microbial EPS are nowadays actively used in various industries such as the food, pharmaceutical, oil and textile industry, due to their colloidal and adhesive properties, and their beneficial effects on liquid rheology (Nwodo et al. 2012)."

\section{REVIEWER 1}


The authors acknowledge the feedback from Reviewer 1 and systematically considered all recommendations provided. Thus, the description and interpretation of the results obtained have been significantly improved in order to generate a better understanding of the experimentation conducted in this paper.

\section{General comments:}

The manuscript submitted by Cantera $S$. et al. is a review and focuses on methane-based bio-transformations. Overall the study is divided into two main parts. In the first part the current state of technologies of the microbial production of ectoine and hydroxyectoine, PHAs and PHBs as well as extracellular polysaccharides and secondary methane-driven bioproducts are summarized and potential strategies to improve the underlying microbial metabolism are discussed. In the second part, bioprocess engineering solutions are shown and pros and cons of bioreactors used today are discussed.

1. The work is written in a too general way and touches the topics only at the surface. Descriptions and explanations throughout the manuscript are very difficult to understand and as in case of the GSMM mostly textbook knowledge.

The authors agree with Reviewer 1 in the sense that the text is sometimes too general and difficult to understand in some sections (i.e Methanotrophs as cell factories through metabolic engineering). This was mainly due to the space limitation and the attempt of the authors to encompass the all recent discoveries in the field from an engineering, biotechnological and molecular biology point of view. However, the result seemed to be a vague and too general description of the current state of the art of methane bioconversion technologies. In this context, the section "Bioreactor configuration..." has been removed from the revised version of this manuscript. Moreover, the section "Methanotrophs as cell factories through metabolic engineering" has been entirely rewritten and more updated information has been included in this specific section to make it easier to follow and enhance its impact. Additionally, a more exhaustive description of the four most promising bioproducts produced from methane oxidation has been included in this revised version. In this context, methanol has been included in this review and the information supported has been complemented with new figures (methanol and PHA production) and a table that 
compiles the main methanotrophic bacteria involved in the production of high added value compounds from methane.

2. The work is too heterogeneous. The two parts (products / bioreactors) are presented without context and it is not clear to the reader why the bioreactors part was included. Concentrating on only one part would give the authors the opportunity to explain the topics more comprehensibly and discuss them with the required scientific quality.

The authors agree with Reviewer 1 on the limited details provided in the original manuscript for the envisaged methane biotransformation processes. This lack of explanation was due to the limited space available. However, in the revised version of this manuscript, the bioreactor part has been deleted and the manuscript has been entirely focused on the biotransformation of methane into bioproducts with a high market value. Hence, novel information and more detailed descriptions about the metabolic pathways, the microbes used and the high market valuable compounds produced have been included in the revised version of this manuscript. In addition, new bioproducts such as methanol, a new table with the microorganisms involved in these processes, as well as two new figures to make more visual the production of PHAs and methanol have been incorporated to the revised version of this manuscript.

3. After reading the manuscript it is not clear why this study should be published. The major goal of the review, the current state of and what is limiting methane-based bioconversions are not well or not described.

The current state of the art and the current limitations of these biotechnologies have been more exhaustively described in this revised manuscript, throughout the addition of new sections referring to different compounds, a more detailed explanation of the current methanotrophic bacteria producing secondary metabolites with a high profit margin and including a new table and figures.

4. The reference list is by far not complete, which in case of a review is a minimum 
requirement (e.g. (just from a quick survey) Environ.Sci.Technol., 2015, 49,4001-4018; J.Environ.Manage., 2016,182, 160; Eng.LifeSc., 2010, 10, 87.102, ...)

The authors apologize for these mistakes and have carefully corrected the reference section in the revised version of this manuscript.

5. The choice of products appears to be selective. Why did the authors left out other prominent and valuable products such as methanol.

The authors apologize for not including this product, which is gaining importance and whose production from methane is attracting an increasing attention worldwide. Therefore, a new section called "Methanol production from methane" has been included in the revised version of this manuscript (pages 6 to 8 ).

\section{REVIEWER 3}

This review gave a broad and general outline of how to use methane to produce other valuable products. Specific comments are listed below:

\section{1) Abstract The authors spent most space talking about what an introduction usually does.}

Please be more specific about potential products to be produced from methane and a variety of microbes to be used as well as fermentation processes involved.

The authors agree with Reviewer 3 on the lack of specific information included in the original abstract about the subject that was further described in the manuscript. Thus, a more detailed explanation along with new information about the potential compounds that can be produced from methane, and the organisms involved in the process, were added to the abstract of this revised manuscript.

"Despite the environmental relevance of $\mathrm{CH}_{4}$ and forthcoming stricter regulations, the development of cost-efficient and environmentally friendly technologies for $\mathrm{CH}_{4}$ abatement is still limited. To date, one of the most promising solutions for the mitigation of this important GHG consists of the bioconversion of $\mathrm{CH}_{4}$ into bioproducts with a high profit margin. In this context, methanotrophs have been already proven as cell-factories of some of 
the most expensive products synthesized by microorganisms. In the case of ectoine $(1000 \$$ $\mathrm{kg}^{-1}$ ), already described methanotrophic genera such as Methylomicrobium can accumulate up to $20 \%$ (ectoine $\mathrm{wt}^{-1}$ ) using methane as the only carbon source. Moreover, $\alpha$ methanotrophs, such as Methylosynus and Methylocystis, are able to store bioplastic concentrations up to 50-60 \% of their total cell content. More than that, methanotrophs are one of the greatest potential producers of methanol and exopolysaccharides. Although this methanotrophic factory could be enhanced throughout metabolic engineering, the valorization of $\mathrm{CH}_{4}$ into valuable metabolites has been already consistently demonstrated under continuous and discontinuous mode, producing more than one compound in the same bioprocess, and using both single strains and specific consortia. This review states the stateof-the-art of this innovative biotechnological platform by assessing its potential and current limitations."

\section{2)Please provide a Table of microbes used and products produced with references listed.}

The authors agree with Reviewer 3 on the fact that the addition of a table compiling the microbes used and substrates produced would enhance the quality of this review. In this regard, Table 1 has been included in order to provide this information.

Moreover, the references listed on the table have been added to the reference section of the revised manuscript.

\section{3)Page 4, please cite a reference for 230+20 mg ectoine g biomass.}

The authors apologize for this error and included the reference requested (Khmelenina et al. 2000) in the revised manuscript (this reference was already part of the reference section) (page 4):

"M. alcaliphilum has been shown to reach intracellular ectoine concentrations up to $230 \pm 20$ mg ectoine $\mathrm{g}$ biomass ${ }^{-1}$ using $\mathrm{CH}_{4}$ as the only carbon and energy source (Khmelenina et al. 2000)". 


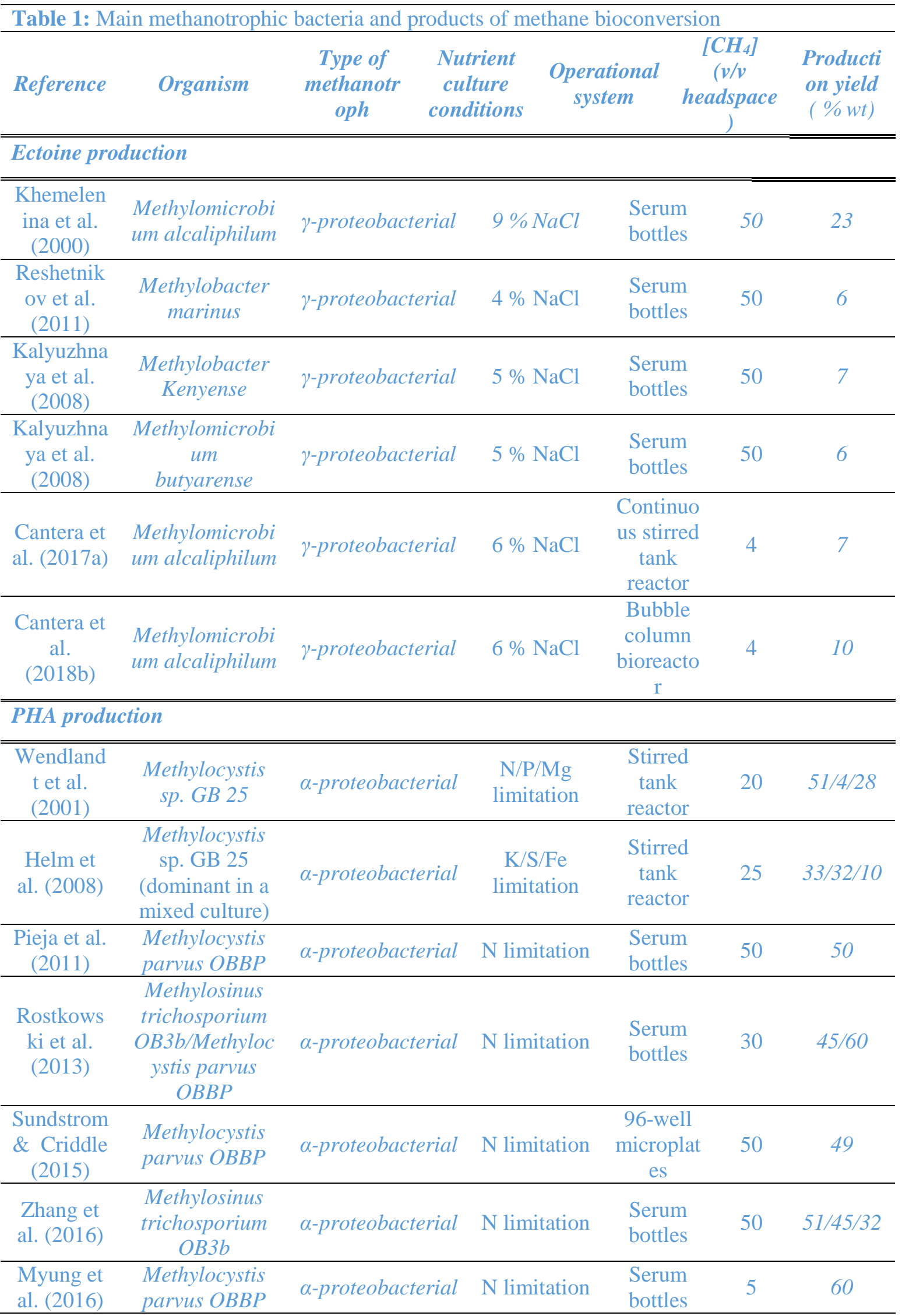




\begin{tabular}{|c|c|c|c|c|c|c|}
\hline $\begin{array}{c}\text { López et } \\
\text { al. (2018) } \\
\end{array}$ & $\begin{array}{c}\text { Methylocystis } \\
\text { hirsuta }\end{array}$ & $\alpha$-proteobacterial & $N$ limitation & $\begin{array}{l}\text { Serum } \\
\text { bottles }\end{array}$ & 35 & 54 \\
\hline $\begin{array}{c}\text { García } \\
\text { Pérez et } \\
\text { al.(2018) }\end{array}$ & $\begin{array}{l}\text { Methylocystis } \\
\text { hirsuta }\end{array}$ & $\alpha$-proteobacterial & N limitation & $\begin{array}{c}\text { gas- } \\
\text { recycling } \\
\text { bubble } \\
\text { column } \\
\text { bioreacto } \\
\text { r } \\
\end{array}$ & 4 & 34 \\
\hline \multicolumn{7}{|c|}{ EPS production } \\
\hline $\begin{array}{c}\text { Malashen } \\
\text { ko et al. } \\
(2001) \\
\end{array}$ & $\begin{array}{c}\text { Methylococcus } \\
\text { sp. }\end{array}$ & $\gamma$-proteobacterial & $\begin{array}{c}\text { High }\left[\mathrm{PO}_{4}{ }^{3-}\right. \\
]\end{array}$ & $\begin{array}{l}\text { Serum } \\
\text { bottles }\end{array}$ & N.R & 38 \\
\hline $\begin{array}{l}\text { Malashen } \\
\text { ko et al. } \\
\text { (2001) }\end{array}$ & $\begin{array}{l}\text { Methylobacter } \\
\text { ucrainicus }\end{array}$ & $\gamma$-proteobacterial & $\begin{array}{l}\text { High } \\
\text { [PO43-] }\end{array}$ & $\begin{array}{c}\text { Chemost } \\
\text { at } \\
\text { cultivatio } \\
\mathrm{n}\end{array}$ & 29 & 55 \\
\hline $\begin{array}{l}\text { Wilhushen } \\
\text { et } \\
\text { al.(2004) }\end{array}$ & $\begin{array}{l}\text { Methanotrophic } \\
\text { consortium }\end{array}$ & $\gamma$-proteobacterial & & $\begin{array}{l}\text { Fermente } \\
\text { rs }\end{array}$ & 38.5 & $\sim 60-80$ \\
\hline $\begin{array}{l}\text { Cantera et } \\
\text { al.(2018b) }\end{array}$ & $\begin{array}{l}\text { Methanotrophic } \\
\text { consortium }\end{array}$ & $\gamma$-proteobacterial & $\begin{array}{c}\text { High }[\mathrm{NaCl}] \\
\text { and } \\
\text { alkalinity }\end{array}$ & $\begin{array}{c}\text { Bubble } \\
\text { column } \\
\text { bioreacto } \\
\mathrm{r} \\
\end{array}$ & 4 & 107 \\
\hline $\begin{array}{l}\text { Cantera et } \\
\text { al.(2018b) }\end{array}$ & $\begin{array}{l}\text { Methylomicrobi } \\
\text { um alcaliphilum }\end{array}$ & $\gamma$-proteobacterial & $\begin{array}{c}\text { High }[\mathrm{NaCl}] \\
\text { and } \\
\text { alkalinity }\end{array}$ & $\begin{array}{c}\text { Bubble } \\
\text { column } \\
\text { bioreacto } \\
\text { r } \\
\end{array}$ & 4 & 79 \\
\hline \multicolumn{7}{|c|}{ Methanol production } \\
\hline $\begin{array}{c}\text { Sugimori } \\
\text { et al. } \\
(1995) \\
\end{array}$ & $\begin{array}{c}\text { Methylosinus } \\
\text { trichosporium } \\
\text { OB3b }\end{array}$ & $\alpha$-proteobacterial & $\begin{array}{c}\text { Cyclopropa } \\
\text { nol }\end{array}$ & $\begin{array}{l}\text { Serum } \\
\text { bottles }\end{array}$ & 25 & 71 \\
\hline $\begin{array}{l}\text { Duan et } \\
\text { al. (2011) }\end{array}$ & $\begin{array}{c}\text { Methylosinus } \\
\text { trichosporium } \\
\text { OB3b } \\
\end{array}$ & $\alpha$-proteobacterial & $\begin{array}{l}\text { High }\left[\mathrm{PO}_{4}{ }^{3-}\right. \\
] \text { and } \mathrm{MgCl}_{2}\end{array}$ & $\begin{array}{l}\text { Serum } \\
\text { bottles }\end{array}$ & 50 & 64 \\
\hline $\begin{array}{c}\text { Han et al. } \\
(2013)\end{array}$ & $\begin{array}{c}\text { Methanotrophic } \\
\text { consortium }\end{array}$ & - & $\begin{array}{l}\mathrm{NaCl} \text { or } \\
\mathrm{NH}_{4} \mathrm{Cl}\end{array}$ & $\begin{array}{l}\text { Serum } \\
\text { bottles }\end{array}$ & 40 & 80 \\
\hline $\begin{array}{l}\text { Hwang et } \\
\text { al. (2015) }\end{array}$ & $\begin{array}{c}\text { Methylosinus } \\
\text { trichosporium } \\
\text { OB3b }\end{array}$ & $\alpha$-proteobacterial & $\begin{array}{l}\text { High }\left[\mathrm{PO}_{4}^{3-}\right. \\
] \text { and EDTA }\end{array}$ & $\begin{array}{l}\text { Serum } \\
\text { bottles }\end{array}$ & 30 & 73.8 \\
\hline
\end{tabular}

\section{4)Page 6, Please explain the RUMP-pathway}

The authors agree with Reviewer 3 on the fact that the RUMP-pathway, as well as the serine pathway, were not well explained in the original manuscript. The information requested by Reviewer 3 was included in this revised version of the manuscript (current page 5). 
"Methanotrophs are divided into two different groups based on their carbon assimilation pathway:

1. $\alpha$-proteobacterial methanotrophs, which utilize the serine cycle for formaldehyde assimilation. In this cycle, methane is converted to formate, which itself is converted to methylene tetrahydrofolate. Methylene $\mathrm{H}_{4} \mathrm{~F}$ condenses with glycine to generate serine.

2. The gamma-proteobacterial methanotrophs, which use the ribulose monophosphate cycle where formaldehyde is condensed with ribulose monophosphate to create a hexulose phosphate, which itself is converted to fructose-6-phosphate (Anthony, 2011).”

The following reference has been included to the references section:

Anthony C. (2011). How half a century of research was required to understand bacterial growth on $\mathrm{C} 1$ and $\mathrm{C} 2$ compounds; the story of the serine cycle and the ethylmalonyl-CoA pathway. Science progress 94, 109-137.

\section{5)Page 8, Please explain in more details about the method used for metabolic engineering, which pathway was redirected and what available techniques for molecular cloning can be applied?}

The information requested by Reviewer 3 has been added to the revised version of this manuscript (page 11):

“GSMMs have been already developed for two methanotrophic bacteria, M. buryatense and M. alcaliphilum 20Z. A model of M. buryatense was first published in 2015 (Torre et al. 2015), which represented the first GSMM published for a methanotroph and contained a total of 841 metabolic reactions. This model was used to elucidate the electron carrier that reduces 
oxygen to water during methane oxidation into methanol. Although, three different theories to explain this step of methane metabolic pathway had been postulated hitherto, the redoxarm mode, the direct coupling mode and the uphill electron transfer (Fig. 4), the GSMM of $M$. buryatense allowed to corroborate the direct coupling mode as the most plausible mechanism due to the comparison of biomass yields and $\mathrm{CH}_{4}: \mathrm{O}_{2}$ consumption ratios. Similarly, a model of M. alcaliphilum $20 \mathrm{Z}$ published in 2018 (Akberdin et al. 2018) confirmed the direct coupling mode as the methane oxidation mechanism. Moreover, this model was subsequently used to find knockout targets for the optimization of the production of 2,3-butanediol (Nguyen et al. 2018). These knockout targets were found by modeling the effects of a knockout using MOMA (Minimization Of Metabolic Adjustment) to simulate the perturbation caused by a gene knockout on the distribution of metabolic fluxes, and the algorithm OptGene (Patil et al. 2005) to find sets of knockouts leading to increased 2,3butanediol productivities. The implementation of a triple knockout of the genes MDH, LDH and ACKr, resulted in a 64\% increase of the production of 2,3-butanediol (Nguyen et al., 2018)."

The following references have been included in the revised version of these manuscript:

Torre A, Metivier A, Chu F, et al. (2015) Genome-scale metabolic reconstructions and theoretical investigation of methane conversion in Methylomicrobium buryatense strain 5G(B1). Microb Cell Fact. 14:188. doi: 10.1186/s12934-015-0377-3.

Nguyen AD, Hwang IY, Lee OK, et al. (2018) Systematic metabolic engineering of Methylomicrobium alcaliphilum $20 \mathrm{Z}$ for 2,3-butanediol production from methane. Metab Eng. 47:323-333. doi: 10.1016/j.ymben.2018.04.010.

\section{6)Page 8, a direct gene-protein-reaction does not apply in metabolic models, please clarify}

A direct gene-protein-reaction is a well-known feature of Genome Scale Metabolic models, so we believe that the reviewer claims that "a direct gene-protein-reaction connection" does not apply because some word in this paragraph made the statement confusing. In this regard, this information has been removed from the manuscript to avoid further misunderstanding. 
7)Fig. 1. Please describe what enzymes/proteins of these genes ectA, ectB, ectC and asK encode for? and also explain how ectoine is accumulated.

The authors apologize for this error and included a more detailed explanation about ectoine accumulation and about the enzymes involved in the ectoine pathway. Moreover, the name of the enzymes involved in ectoine production has been included in figure 1 legend (current page 3):

"In response to a high salinity of the growth medium, these methanotrophic bacteria accumulate ectoine as the major osmoprotective compound inside the cytoplasm without disturbing the cell's metabolism (including nucleic acid and lipid metabolism) even at high molar cytoplasmic concentrations. The ectoine biosynthesis pathway in M. alcaliphilum $20 Z$ has been deeply studied (Mustakhimov et al. 2009). It is similar to the pathway employed by halophilic/halotolerant heterotrophs and involves three specific enzymes: diaminobutyric acid (DABA) aminotransferase (EctB), DABA acetyltransferase (EctA), and ectoine synthase (EctC) (encoded by the conserved gene cluster, ectABC), which together catalyze the conversion of the precursor aspartate into ectoine, plus an additional gene of aspartokinase (Ask) conforming an ectABC-ask cluster (Fig. 1) (Reshetnikov et al. 2011).”

This reference has been included in the revised version of this manuscript:

Mustakhimov II, Reshetnikov AS, Glukhov AS, et al. (2009) Identification and characterization of EctR1, a new transcriptional regulator of the ectoine biosynthesis genes in the halotolerant methanotroph Methylomicrobium alcaliphilum 20Z. J Bacteriol.192(2):410-7.

"Fig. 1. Accumulation of ectoine in M. alcaliphilum 20Z, pathway for the synthesis of ectoine. Adapted from Pastor et al. (2010). ectA encodes for the protein DABA acetyltransferase (EctA), ectB for diaminobutyric acid (DABA) aminotransferase (EctB), ectC for ectoine synthase (EctC) and ask for aspartokinase (Ask)." 
We hope that these modifications will comply with the requests of World Journal of Microbiology \& Biotechnology. Please do not hesitate to contact us at your convenience if you need further information.

\section{Sara Cantera \& Raúl Muñoz}




\title{
Bio-conversion of methane into high profit margin compounds: An innovative, environmentally friendly and cost-effective platform for methane abatement.
}

\author{
Sara Cantera ${ }^{1}$, Sergio Bordel ${ }^{1,2}$, Raquel Lebrero ${ }^{1,2}$, Juan Gancedo ${ }^{1}$, Pedro A. García \\ Encina $^{1,2}$ and Raúl Muñoz ${ }^{1,2 *}$
}

1-Department of Chemical Engineering and Environmental Technology, School of Industrial Engineering, Valladolid University, Dr. Mergelina, s/n, Valladolid, Spain.

2- Institute of Sustainable Processes, Universidad de Valladolid, Dr. Mergelina, s/n, Valladolid, Spain

*Corresponding author: mutora@iq.uva.es

\begin{abstract}
Despite the environmental relevance of $\mathrm{CH}_{4}$ and forthcoming stricter regulations, the development of cost-efficient and environmentally friendly technologies for $\mathrm{CH}_{4}$ abatement is still limited. To date, one of the most promising solutions for the mitigation of this important GHG consists of the bioconversion of $\mathrm{CH}_{4}$ into bioproducts with a high profit margin. In this context, methanotrophs have been already proven as cell-factories of some of the most expensive products synthesized by microorganisms. In the case of ectoine (1000 $\left.\$ \mathrm{~kg}^{-1}\right)$, already described methanotrophic genera such as Methylomicrobium can accumulate up to 20 $\%$ (ectoine $\mathrm{wt}^{-1}$ ) using methane as the only carbon source. Moreover, $\alpha$-methanotrophs, such as Methylosynus and Methylocystis, are able to store bioplastic concentrations up to 50-60\% of their total cell content. More than that, methanotrophs are one of the greatest potential producers of methanol and exopolysaccharides. Although this methanotrophic factory could be enhanced throughout metabolic engineering, the valorization of $\mathrm{CH}_{4}$ into valuable metabolites has been already consistently demonstrated under continuous and discontinuous mode, producing more than one compound in the same bioprocess, and using both single strains and specific consortia. This review states the state-of-the-art of this innovative biotechnological platform by assessing its potential and current limitations.
\end{abstract}

Keywords: Methane abatement, market-value products, bio-transformation, ectoine, methanotrophs. 


\section{Introduction}

The bioconversion of $\mathrm{CH}_{4}$ into high added value products using a bio-refinery approach has emerged as one of the most promising strategies to mitigate methane emissions (Khmelenina et al., 2015; Strong et al., 2016a; Strong et al., 2016b). In this regard, $\mathrm{CH}_{4}$-laden emissions can be used by methanotrophs to synthesize essential compounds that have a high market value, such as ectoines, biopolymers, methanol or exopolysaccharides. This bioconversion could be implemented to mitigate both, diluted $\mathrm{CH}_{4}$ emissions from landfills and coal mines, and biogas from waste/wastewater treatment facilities, generating high added value bioproducts out of these off-gases (Cal et al. 2016; Strong et al. 2016b). Although optimization from a micro and macroscopic perspective is still required for enhancing microbial $\mathrm{CH}_{4}$ bioconversion, this innovative $\mathrm{CH}_{4}$ biotransformation can turn methane elimination into a cost-effective and costcompetitive process.

\section{Ectoine and hydroxyectoine production from methane}

Ectoine and its hydroxylated derivate (hydroxyectoine) are naturally produced by a wide range of halotolerant bacteria to maintain cell osmotic integrity at high salinities. The outstanding properties of ectoines as heat protectors and protein and nucleic acids stabilizers (Pastor et al. 2010) has made them a target product for their commercialization in the pharmaceutical industry (retail value of US\$1000-1500 kg ${ }^{-1}$ and global demand of 15000 tones year ${ }^{-1}$ ) (Strong et al. 2016b).

Despite their value and demand, ectoines are only commercialized by the company BITOP (Witten, Germany), which synthesizes them on a scale of tons using the heterotrophic bacteria Halomonas elongata. Nevertheless, the upstream of the production process is still inefficient 
due to the high amount of nutrients, oxygen and time required, besides entailing a complex and expensive downstream processing (Kunte et al. 2014).

Since 1997, new species of halotolerant $\mathrm{CH}_{4}$ oxidizing bacteria capable of synthesizing ectoine have been identified. Most of them belong to the genera Methylomicrobium, i.e. M. alcaliphilum, $M$. buryatense, $M$. kenyense or $M$. japanense, although other bacteria such as Methylobacter marinus and Methylohalobius cremeensis are also ectoine producers (Khmelenina et al., 1997; Stępniewska et al. 2014; Khmelenina et al. 2015). In response to a high salinity of the growth medium, these methanotrophic bacteria accumulate ectoine as the major osmoprotective compound inside the cytoplasm without disturbing the cell's metabolism (including nucleic acid and lipid metabolism) even at high molar cytoplasmic concentrations. The ectoine biosynthesis pathway in M. alcaliphilum $20 Z$ has been deeply studied (Mustakhimov et al. 2009). It is similar to the pathway employed by halophilic/halotolerant heterotrophs and involves three specific enzymes: diaminobutyric acid (DABA) aminotransferase (EctB), DABA acetyltransferase (EctA), and ectoine synthase (EctC) (encoded by the conserved gene cluster, ectABC), which together catalyze the conversion of the precursor aspartate into ectoine, plus an additional gene of aspartokinase (Ask) conforming an ectABC-ask cluster (Fig. 1) (Reshetnikov et al. 2011). Ask isoenzyme supports an independent ectoine synthesis that results in the presence of basal activities of biosynthesis and a relatively high salt tolerance, making this methanotrophic bacteria a workhorse for $\mathrm{CH}_{4}$ mitigation combined with ectoine production (Khmelenina et al. 2015). On the other hand, hydroxyectoine is formed by a subgroup of ectoine producers through a position- and stereospecific hydroxylation of ectoine, an enzymatic reaction catalyzed by the ectoine hydroxylase (EctD). A silent gene of ectoine hydroxylase (EctD), which is supposed to be responsible for ectoine transformation into hydroxyectoine, has been found in M. alcaliphilum. However, the 
conditions triggering ectD expression or hydroxyectoine accumulation have not been yet elucidated (Reshetnikov et al. 2006; Khmelenina et al. 2015).

$<$ Fig.1>

M. alcaliphilum has been shown to reach intracellular ectoine concentrations up to $230 \pm 20$ mg ectoine $\mathrm{g}$ biomass ${ }^{-1}$ using $\mathrm{CH}_{4}$ as the only carbon and energy source (Khmelenina et al. 2000), which largely exceeded the amounts synthesized by M. marinus and M. kenyense (60 and $70 \mathrm{mg} \mathrm{g}$ biomass $^{-1}$ ) (Kalyuzhnaya et al. 2008; Khmelenina et al. 2015). Moreover, the ability of this bacterium to produce ectoine in continuous bio-reactors using $\mathrm{CH}_{4}$ (from emissions with a $\mathrm{CH}_{4}$ concentration of $4 \%(\mathrm{v} / \mathrm{v})$ ) was recently demonstrated (Cantera et al. 2017a). These authors also confirmed the feasibility of producing ectoine by $M$. alcaliphilum through fed-batch fermentations in a biomilking process, which resulted in extracellular concentrations of $253.4 \pm 55.1 \mathrm{mg} \mathrm{L}^{-1}$ and in a recovery of $\sim 70 \%$ of the total intra-cellular ectoine accumulated (similar values to the ones obtained in the industrial production of ectoine by Halomonas elongata (75\%))(Cantera et al. 2017b). Nevertheless, no methanotroph has been yet described as hydroxyectoine producer, and to the best of our knowledge, there is only a study carried out by Cantera et al. (2018b) that demonstrated the conversion of methane into hydroxyectoine using a consortium of methanotrophic and non-methanotrophic bacteria (table 1).

\section{$\langle$ Table.1>}

\section{Bioplastics from methane}

Polyhydroxyalkanoates (PHAs) like poly-3-hydroxybutyrate (PHB) and also the polymer poly(3-hydroxybutyrate-co-3-hydroxyvalerate) (PHBV) are biological biopolyesters synthesized under nutrient-limiting and carbon-excess conditions by a large variety of microorganisms as carbon and/or energy storage resources (Pieja et al. 2017). Their 
outstanding mechanical properties, similar to those of polypropylene and polyethylene, together with their biodegradability and biocompatibility, make PHAs an interesting and potential substitute to oil-based plastics (Myung et al. 2017). As result, PHAs are currently industrially produced by nearly thirty corporations, Meredian Inc. (with a yearly production of $300 \mathrm{kt}$ ) and Bio-On (yearly production $~ 10 \mathrm{kt}$ ) being the leading manufacturers in U.S. and Europe, respectively (Cantera et al. 2018a). Glucose and fructose are the most common feedstock used for the commercial production of PHAs. However, the high price of those carbon sources, which accounts for 30-40\% of the overall production costs, still hinders PHAs commercialization due to their noncompetitive market price $\left(4-20 € \mathrm{Kg}_{\mathrm{PHA}}{ }^{-1}\right)($ Koller et al. 2017). In this context, the utilization of $\mathrm{CH}_{4}$ as a feedstock for PHAs production would considerably reduce production costs while mitigating climate change (Cal et al. 2016; Pieja et al. 2017).

Methanotrophs are divided into two different groups based on their carbon assimilation pathway:

1. $\alpha$-proteobacterial methanotrophs, which utilize the serine cycle for formaldehyde assimilation. In this cycle, methane is converted to formate, which itself is converted to methylene tetrahydrofolate. Methylene $\mathrm{H}_{4} \mathrm{~F}$ condenses with glycine to generate serine.

2. The gamma-proteobacterial methanotrophs, which use the ribulose monophosphate cycle where formaldehyde is condensed with ribulose monophosphate to create a hexulose phosphate, which itself is converted to fructose-6-phosphate (Anthony, 2011).

Most of the studies reporting PHAs production using methanotrophic bacteria have been conducted with $\alpha$-proteobacterial methanotrophs, since PHAs synthesis is supposed to be linked with the serine cycle (Fig.2). Thus, acetyl-CoA molecules produced in the serine cycle 
are transformed into PHAs via reactions catalyzed by the enzymes $\beta$-ketothiolase (phaA), acetoacetyl-CoA reductase (phaB), and PHAs synthase (phaC) (Fig. 2). Although qualitative data regarding PHAs production have been reported in RuMP-pathway $\gamma$ proteobacteria, such as Methylomicrobium (Karthikeyan et al. 2015) their potential is still uncertain and several studies have shown that RuMP-pathway methanotrophs may be incapable of PHAs synthesis. Thus, serine-pathway methanotrophs such as the genera Methylocystis and Methylosinus represent, under nutrient-limited conditions (usually N-, P- or Mg-limitation), the main PHAs producers to date (table 1). Indeed, several studies have demonstrated that these methanotrophs are a potential source of bioplastics, achieving PHAs contents ranging from 20 to $60 \%$ (wt) using either dilute methane emissions or biogas as a feedstock (Strong et al. 2016b, Pieja et al. 2017; García-Pérez et al. 2018). In this sense, the companies Mango Materials and Newlight Technologies (U.S.) are pioneering corporations targeting PHB production from $\mathrm{CH}_{4}$ emissions (Pieja et al. 2017; Cantera et al. 2018a).

\section{$<$ Fig.2>}

\section{Methanol production from methane}

Methanol $\left(\mathrm{CH}_{3} \mathrm{OH}\right)$ has become in the past years a highly demanded product (70-100 mtpy) due to its favorable chemical and physical fuel properties (Strong et al., 2016a; Methanol institute [2018a]). Methanol represents a cheap, easily transported and environmentally friendly alternative to conventional fuels (energy density 15.6-15.8 $\mathrm{MJ} \mathrm{L}^{-1}$ ) (Bjorck et al., 2018). Moreover, its chemical simplicity makes it an interesting versatile building-block for the production of many value-added products such as olefins, propylene, formaldehyde and other organic acids and alcohols (Zhen \& Wang, 2015).

Methanol price currently amounts to $493 \$$ ton $^{-1}$ and is produced by a wide range of companies using a variety of industrial processes, METHANEX and ATLANTIC METHANOL being 
some of the most important ones (Methanol institute (2018b)). Nowadays, one of the most innovative platforms for its production is the transformation of methane into methanol, which makes the process more cost-effective and at the same time helps to eliminate the second most important greenhouse gas nowadays (Bjorck et al., 2018). Although, the production of methane from methanol has been attempted from a biological and chemical point of view (Fig 3A), the only process currently used in the industry is the chemical methane-to-methanol conversion, (Zhen \& Wang, 2015) which is developed in a two-step process, first converting methane in syngas by steam reforming (Eq.1) and then in methanol by a thermo-catalytic process (Eq.2) (Bjorck et al., 2018):

$$
\begin{array}{lll}
\text { [1] } & \mathrm{CH}_{4}+\mathrm{H}_{2} \mathrm{O} \leftrightarrow \mathrm{CO}+3 \mathrm{H}_{2} & \Delta_{\mathrm{r}} \mathrm{H}^{\mathrm{o}}=+206 \mathrm{KJ} \mathrm{mol}^{-1} \\
\text { [2] } & \mathrm{CO}+2 \mathrm{H}_{2} \leftrightarrow \mathrm{CH}_{3} \mathrm{OH} & \Delta_{\mathrm{r}} \mathrm{H}^{\mathrm{o}}=-90 \mathrm{KJ} \mathrm{mol}^{-1}
\end{array}
$$

Nevertheless, this industrial methanol production is still ineffective and costly since it requires expensive equipment, an intensive energy usage and a methane-off-laden-stream free of impurities. In addition, the use of extreme conditions causes secondary reactions, decreasing the conversion and selectivity ( $<25 \%$ and $<70 \%$, respectively) (Sheets et al., 2016; Bjorck et al., 2018).

In this context, the biological conversion of methane-to-methanol is currently gaining attention as an environmentally friendly and inexpensive alternative to its chemical production (Fig 3.B). This process consists on a fast, selective and efficient one-step transformation of methane to methanol and could overcome the current limitations of its chemical conversion (Bjorck et al., 2018). However, this bioconversion platform requires first, an efficient strategy to avoid the bacteria to oxidize methanol into formaldehyde by the enzyme methanol dehydrogenase (MDH). In this regard, metal chelating agents (EDTA >0.05 mM), cyclopropane, cyclopropanol (>67 nM), dithioreinol, phenylhidrazine, iodoacetate, sodium chloride $(>100$ 
$\mathrm{mM})$, magnesium chloride ( $>5 \mathrm{mM})$, ammonium chloride $(>40 \mathrm{mM})$ and high concentrations of phosphate ( $>40 \mathrm{mM})$, have been identified as some of the most successful inhibitors (Sheets et al., 2016; Bjorck et al., 2018). In addition, a high concentration of carbon dioxide in the gas phase seems to result in a partial MDH inhibition (Chistoserdova \& Kalyuzhnaya, 2018). Secondly, this bioconversion platform requires the addition of an organic substrate as reducing power source to uphold the methanotrophs activity and prevent decreasing methanol synthesis (Pieja et al., 2017). Methanotrophs naturally convert methane to methanol using sMMO and/or pMMO, which require two electrons supplied by the cell in the form of NADH or cytochrome $\mathrm{c}(\mathrm{CytC})$. These electrons are generated during the oxidation of methanol to carbon dioxide (Fig 3 B) (Bjorck et al., 2018). For this purpose, formate (15-40 mM) is commonly added during the production of methanol, but its high price limits its application on a commercial scale. Hence, other alternative such as formaldehyde (which can have inhibitory effects) and PHAs (which also limits process economics) are under investigation (Xin et al., 2007: Mahmoud, 2017).

\section{$<$ Fig.3>}

Both alpha and gamma methanotrophs are able to produce methanol, although the majority of current investigations are focused on alpha proteobacteria as a bioconversion platform (Mahmoud, 2017). In this regard, conversion efficiencies up to $80 \%$ have been described by Han et al., (2013) using a methanotrophic consortium formed mainly by Methylosinus sporium NCIMB 11126, Methylosinus trichosporium OB3b and Methylococcus capsulatus Bath, and $\mathrm{NaCl}(100 \mathrm{mM})$ or $\mathrm{NH}_{4} \mathrm{Cl}(40 \mathrm{mM})$ as $\mathrm{MDH}$ inhibitor. A pure strain of Methylosinus trichosporium $O B 3 b$ (table 1) is typically used with conversion efficiencies ranging from 61 to $74 \%$, using high concentrations of phosphate, magnesium chloride, cyclopropanol or a combination of phosphate and EDTA as MDH inhibitors (Sugimori et al., 1995; Duan et al., 2011; Hwang et al., 2015). 


\section{Extracellular polysaccharides and secondary methane-driven bioproducts}

Microbial extracellular polysaccharides (EPS) constitute a wide diversity of molecules conformed by homopolysaccharides or heteropolysaccharides combined with proteins and lipids. Bacteria secret them to the surrounding environment for different purposes, such as adherence of cells to surfaces, migration, protection from predators, toxics or extreme conditions. Microbial EPS are nowadays actively used in various industries, such as the food, pharmaceutical, oil and textile industry, due to their colloidal and adhesive properties, and their beneficial effects on liquid rheology (Nwodo et al. 2012). The main constraint to the full commercialization of biological EPS is its production price, mostly related to substrate cost and downstream processing (Freitas et al. 2011). In fact, CPKelco, Merck, Pfizer and Prasinotech Ltd. are companies currently focused on commercializing microbial exopolysaccharides such as xanthan (4-13€ $\mathrm{Kg}^{-1}$ ) and dextran (30-50€ $\mathrm{Kg}^{-1}$ ), though productivities and costs derived from the purchase of the carbon source and downstream still hamper their industrial production (Freitas et al. 2011). In this context, the production of EPS using methanotrophic bacteria has attracted an increasing attention because $\mathrm{CH}_{4}$ represents an alternative free feedstock. Under non-stressing conditions, EPS productions of $0.03-0.43 \mathrm{~g} \mathrm{~g}^{-}$ ${ }^{1}$ biomass using gamma methanotrophs (Methylobacter, Methylomonas) have been reported (Malashenko et al. 2001). Moreover, recent studies observed that acidification, high salinity and low $\mathrm{N}$ concentrations positively influence EPS excretion by microorganisms, whereas EPS accumulation can be inhibit if $\mathrm{CH}_{4}$ and $\mathrm{O}_{2}$ diffusion to the cells is limited (Wilshusen et al. 2004; Hernández et al. 2015). In this context, a recent publication demonstrated that a consortium composed of methanotrophic and non-methanotrophic bacteria (i.e. Halomonas, Marinobacter, Methylophaga and Methylomicrobium) was able to synthetize ectoine and accumulate EPS at concentrations up to $2.6 \mathrm{~g}$ EPS L $^{-1}$ during methane biodegradation under high salinity and alkalinity (Cantera et al., 2018b). Overall, the combination of stress 
environmental conditions and high microbial diversity resulted in EPS yields higher than those typically obtained in non-extremophile methanotrophic cultures (table 1).

\section{Methanotrophs as cell factories through metabolic engineering}

Although the availability of sequenced genomes of methanotrophic organisms (www.methanotroph.org) allows a more rigorous investigation of methanotrophic genomics and metabolomics (Campbell et. al. 2011), the limited amount of techniques to deliver genetic material into methanotrophs and the still poor understanding of their metabolism make the genetic manipulation of methanotrophs still scarce.

The first examples of transformation of methanotrophic bacteria were carried out by conjugation with E. coli donors, in particular, the strain S17-1 (Simon et al, 1983). In these studies, conjugation was performed in plates in which the methanotrophic growth medium was supplemented with nutrients suitable for the donor strain and incubated in a methanecontaining atmosphere. The selection of methanotrophs was carried out by using naladixic acid or rifamycin, as many methanotrophs are resistant to these antibiotics. However, this method was slow and presented a low efficiency. More recent research has successfully used electroporation to deliver DNA in methanotrophs such as Methylocystis sp. SC2 (Baani \& Liesack, 2008) and M. silvestris BL2 (Crombie \& Murrell, 2011). In fact, there is already a high variety of replicating vectors that can be used to express heterologous genes in methanotrophs, some of the most used vector families being IncP, pBBR and IncQ. Moreover, gene deletions or insertions into the chromosome can be carried out using homologous recombination with large flanking regions (of at least $500 \mathrm{bp}$ in each flank).

A popular tool that has gained importance these days to improve the production of valuable metabolites is the rational design of metabolic engineering strategies called Genome Scale 
Metabolic Models (GSMMs) (Liu et al. 2010). These models can be used to predict the outcome of genetic manipulations, saving time and experimental resources in the process of strain optimization. There are currently a wide number of tools for the automated reconstruction of GSMMs from genomic sequences, such as the SEED server (Henry et al. 2010) and the RAVEN toolbox (Agren et al. 2013).

GSMMs have been already developed for two methanotrophic bacteria, $M$. buryatense and $M$. alcaliphilum 20Z. A model of M. buryatense was first published in 2015 (Torre et al. 2015), which represented the first GSMM published for a methanotroph and contained a total of 841 metabolic reactions. This model was used to elucidate the electron carrier that reduces oxygen to water during methane oxidation into methanol. Although, three different theories to explain this step of methane metabolic pathway had been postulated hitherto, the redox-arm mode, the direct coupling mode and the uphill electron transfer (Fig. 4), the GSMM of M. buryatense allowed to corroborate the direct coupling mode as the most plausible mechanism due to the comparison of biomass yields and $\mathrm{CH}_{4}: \mathrm{O}_{2}$ consumption ratios. Similarly, a model of $M$. alcaliphilum 20Z published in 2018 (Akberdin et al. 2018) confirmed the direct coupling mode as the methane oxidation mechanism. Moreover, this model was subsequently used to find knockout targets for the optimization of the production of 2,3-butanediol (Nguyen et al. 2018). These knockout targets were found by modeling the effects of a knockout using MOMA (Minimization Of Metabolic Adjustment) to simulate the perturbation caused by a gene knockout on the distribution of metabolic fluxes, and the algorithm OptGene (Patil et al. 2005) to find sets of knockouts leading to increased 2,3-butanediol productivities. The implementation of a triple knockout of the genes $\mathrm{MDH}, \mathrm{LDH}$ and $\mathrm{ACKr}$, resulted in a $64 \%$ increase of the production of 2,3-butanediol (Nguyen et al., 2018).

$<$ Fig. $4>$ 


\section{Current biotechnological limitations and future prospects}

Despite the potential of $\mathrm{CH}_{4}$-based bioproducts to develop a versatile and efficient $\mathrm{GHG}$ abatement platform, these biotechnologies can still not outcompete to traditional fermentation and physical-chemical methods that serve the market these days. To this end the costefficiency, productivity and competitiveness of these biotechnologies has to be of prior necessity.

On the one hand, this platform can be enhanced from a biotechnological point of view by spanning the range of products obtained from methanotrophic bacteria, laying emphasis on the multi-production of several compounds in a single bio-process from a methane bio-refinery approach (Cantera et al., 2017b). In this regard, gamma proteobacterial methanotrophs, which assimilate methane through pathways leading to pyruvate formation, could be used as cell factories for the co-production of single cell protein, ectoine, lactate, isobutanol, surface layers and some therapeutics such as methanobactin (Khmelenina et al. 2015; DiSpirito et al. 2016; Strong et al. 2016b). Similarly, alpha Proteobacteria, which use the acetyl-CoA pathway, could be used in the biosynthesis of derivatives of ethanol, butanol, acetone, fatty acids and PHAs. However, a deeper research about the different metabolites that can be produced simultaneously and the carbon fluxes during these metabolic pathways are an essential requirement.

Moreover, the use of methanotrophic consortia, which can ensure higher productivities as well as better bioreactor stability and resilience, could overcome the current problems of low productivity characteristic of pure methanotrophic strains and could help to enhance these biotechnologies. Although, research to elucidate the best combination of methanotrophic and non-methanotrophic bacteria for the production of the target bioproduct is still required, the only current factories commercializing their methane based compounds (UniBio and Calysta) 
use consortia conformed by methanotrophic bacteria and heterotrophs and obtain productivities of up to $4 \mathrm{~kg}$ biomass $\mathrm{m}^{-3} \mathrm{~h}^{-1}$ (Ritala et al. 2017).

Additionally, from an engineering perspective, the implementation of innovative suspendedgrowth bioreactors is the most suitable configuration for the bioconversion of $\mathrm{CH}_{4}$-laden gas streams into added value bioproducts and their subsequent recovery, tubular airlift loop bioreactors and suspended-growth pressurized bioreactors being the most promising configurations out of all of them. The latter bioreactor configurations are capable of handling a large biomass concentration while providing a high gas-liquid mass transfer due to the forced flow recirculation loop and the high pressure maintain in the bioreactor (Petersen et al., 2017, Cantera et al., 2018a).

On the other hand, metabolic engineering and molecular biology are required to redirect the carbon metabolic fluxes towards the bioproducts of interest and to improve product recovery by enzyme modification, which will ultimately increase methane bioconversion productivities. In this sense, current research should be focused on the improvement of MMO expression. The two main approaches to improve methane oxidation rates are the overexpression of pMMO in order to have more copies of the enzyme in the membrane, and the improvement of pMMO through protein engineering. The first approach could face limitations such as the low membrane surface available, while protein engineering requires a good knowledge of methane oxidation mechanisms, which is so far lacking. An alternative approach could be based on random mutagenesis at the pMMO catalytic sites and selection of the mutants that allow faster growth rates.

Finally, it should be highlighted that the initial research conducted to date about the production of high profit margin compounds using methanotrophs have opened a new field full of possibilities for the use of methanotrophs as bioconversion platforms of the second most important GHG. 


\section{Acknowledgements}

This research was funded by the Spanish Ministry of Economy and Competitiveness, the European FEDER program and the European Commission (CTM2015-73228-JIN, H2020MSCA-IF-2016: CH4BioVal-GA:750126 and Red NOVEDAR). The financial support from the regional government of Castilla y León and the Sustainable Processes Institute are also gratefully acknowledged (UIC71).

\section{References}

Agren R, Liu L, Shoaie S, et al. (2013) The RAVEN Toolbox and Its Use for Generating a Genomescale Metabolic Model for Penicillium chrysogenum. PLoS Comput. Biol., 9(3): e1002980. doi: 10.1371/journal.pcbi.1002980

Akberdin IR, Thompson M, Hamilton R, et al. (2018) Methane utilization in Methylomicrobium alcaliphilum 20ZR: A systems approach. Sci Rep., 8, 2512. doi: 10.1038/s41598-018-20574-z Anthony C (2011). How half a century of research was required to understand bacterial growth on C1 and $\mathrm{C} 2$ compounds; the story of the serine cycle and the ethylmalonyl-CoA pathway. Sci. prog., 94, 109-137.

Baani, M, \& Liesack, W (2008) Two isozymes of particulate methane monooxygenase with different methane oxidation kinetics are found in Methylocystis sp. strain SC2. Proc. Natl. Acad. Sci. US A, 105 (29), 10203-8.

Bjorck CE, Dobson PD \& Pandhal J (2018). Biotechnological conversion of methane to methanol: evaluation of progress and potential. AIMS Bioengineering, 5(1), 1-38. ISSN 2375-1495. doi: 10.3934/bioeng.2018.1.1.

Cal AJ, Sikkema WD, Ponce MI, et al. (2016) Methanotrophic production of polyhydroxybutyrate-cohydroxyvalerate with high hydroxyvalerate content. Int. J. Biol. Macromol., 87:302-307. doi: 10.1016/j.ijbiomac.2016.02.056

Cantera S, Lebrero R, Rodríguez E, et al. (2017a) Continuous abatement of methane coupled with 
ectoine production by Methylomicrobium alcaliphilum 20Z in stirred tank reactors: A step further towards greenhouse gas biorefineries. J. Clean Prod., 152:134-141. doi: 10.1016/j.jclepro.2017.03.123

Cantera S, Lebrero R, Rodríguez S, et al. (2017b) Ectoine bio-milking in methanotrophs: A step further towards methane-based bio-refineries into high added-value products. Chem. Eng. J., 328:44-48. doi: 10.1016/j.cej.2017.07.027

Cantera S, Muñoz R, Lebrero R, et al. (2018a) Technologies for the bioconversion of methane into more valuable products. Curr. Opin. Biotechnol., 50:128-135.

Cantera S, Sánchez-Andrea I, Lebrero R, et al. (2018b) Multi-production of high added market value metabolites from diluted methane emissions via methanotrophic extremophiles. Bioresour Technol., 267:401-407. doi: 10.1016/j.biortech.2018.07.057

Campbell MA, Nyerges G, Kozlowski JA, et al. (2011) Model of the molecular basis for hydroxylamine oxidation and nitrous oxide production in methanotrophic bacteria, FEMS Microb.Lett., 322(1): 82-89, https://doi.org/10.1111/j.1574-6968.2011.02340.x

Chistoserdova L \& Kalyuzhnaya MG. (2018). Current trends in methylotrophy. Trends in Microbiol., 26:703-714.

Crombie A \& Murrell C. (2011). Chapter eight - Development of a System for Genetic Manipulation of the Facultative Methanotroph Methylocella silvestris BL2. Methods in Enzymol., 495: 119133. https://doi.org/10.1016/B978-0-12-386905-0.00008-5.

DiSpirito AA, Semrau JD, Murrell JC, et al. (2016) Methanobactin and the Link between Copper and Bacterial Methane Oxidation. Microbiol. Mol. Bio.1 Rev., 80:387-409. doi:

\subsection{8/MMBR.00058-15}

Duan C, Luo M, \& Xing X (2011). High-rate conversion of methane to methanol by Methylosinus trichosporium OB3b. Bioresour. Technol.,102(15), 7349-7353. doi:10.1016/j.biortech.2011.04.096

Freitas F, Alves VD \& Reis MAM (2011) Advances in bacterial exopolysaccharides: From production to biotechnological applications. Trends Biotechnol., 29(8):388-398.

García-Pérez T, López JC, Passos F, et al. (2018) Simultaneous methane abatement and PHB 
production by Methylocystis hirsuta in a novel gas-recycling bubble column bioreactor. Chem. Eng. J., 334:691-697. doi: 10.1016/j.cej.2017.10.106

Han JS, Ahn CM, Mahanty B, et al. (2013) Partial oxidative conversion of methane to methanol through selective inhibition of methanol dehydrogenase in methanotrophic consortium from landfill cover soil. Appl. Biochem. Biotechnol., 171(6), 1487-1499. doi:10.1007/s12010-0130410-0

Hwang IY, Hur DH, Lee JH, et al. (2015) Batch conversion of methane to methanol using Methylosinus trichosporium OB3b as biocatalyst. J. Microbiol. Biotechnol., 25(3), 375-380. doi:10.4014/jmb.1412.12007

Helm J, Wendlandt KD, Jechorek M, et al. (2008) Potassium deficiency results in accumulation of ultra-high molecular weight poly- $\beta$-hydroxybutyrate in a methane-utilizing mixed culture. J. Appl. Microbiol., 105:1054-1061. doi: 10.1111/j.1365-2672.2008.03831.x.

Henry CS, DeJongh M, Best AA, et al. (2010) High-throughput generation, optimization and analysis of genome-scale metabolic models. Nat. Biotechnol. 28: 977-982. doi: 10.1038/nbt.1672

Hernández J, Gómez-Cuervo S \& Omil F. (2015) EPS and SMP as stability indicators during the biofiltration of diffuse methane emissions. Water Air Soil Pollut., 226(10):1-12. doi: $10.1007 / \mathrm{s} 11270-015-2576-2$

Kalyuzhnaya MG, Khmelenina V, Eshinimaev B, et al. (2008) Classification of halo (alkali) philic and halo (alkali) tolerant methanotrophs provisionally assigned to the genera Methylomicrobium and Methylobacter and emended description of the genus Methylomicrobium. Int. J. Syst. Evol. Microbiol., 58:591-596 .

Karthikeyan OP, Chidambarampadmavathy K, Nadarajan S, et al. (2015). Effect of $\mathrm{CH}_{4} / \mathrm{O}_{2}$ ratio on fatty acid profile and polyhydroxybutyrate content in a heterotrophic-methanotrophic consortium. Chemosphere, 141:235-242.

Khmelenina VN, Kalyuzhnaya MG, Starostina NG et al., (1997) Isolation and Characterization of Halotolerant Alkaliphilic Methanotrophic Bacteria from Tuva Soda Lakes. Curr. Microbiol., 35:257-261. doi: 10.1007/s002849900249

Khmelenina, VN, Sakharovskii VG, Reshetnikov AS, et al. (2000). Synthesis of osmoprotectants 
by halophilic and alkaliphilic methanotrophs. Microbiology, 69: 381.

Khmelenina VN, Rozova ON, But SY, et al. (2015) Biosynthesis of secondary metabolites in methanotrophs: Biochemical and genetic aspects (Review). Appl. Biochem. Microbiol., 51: 150. https://doi.org/10.1134/S0003683815020088

Koller M, Maršálek L, de Sousa Dias MM, et al. (2017) Producing microbial polyhydroxyalkanoate (PHA) biopolyesters in a sustainable manner. N. Biotechnol., 37:24-38

Kunte HJ, Lentzen G \& Galinski EA. (2014) Industrial Production of the Cell Protectant Ectoine: Protection Mechanisms, Processes, and Products. Curr Biotechnol., 3:10-25. doi: $10.2174 / 22115501113026660037$

Liu L, Agren R, Bordel S \& Nielsen J (2010) Use of genome-scale metabolic models for understanding microbial physiology. FEBS Lett. 584(12):2556-2564. doi:

10.1016/j.febslet.2010.04.052

López JC, Arnáiz E, Merchán L, et al. (2018) Biogas-based polyhydroxyalkanoates production by Methylocystis hirsuta: A step further in anaerobic digestion biorefineries, Chem.Eng. J., 333:529-536. doi:10.1016/j.cej.2017.09.185.

Mahmoud, AMA. (2017) Biological Conversion Process of Methane into Methanol Using Mixed Culture Methanotrophic Bacteria Enriched from Activated Sludge System.Dissertation. University of York, Canada.

Malashenko IP, Pirog TP, Romanovskaia V, et al (2001) Search for methanotrophic producers of exopolysaccharides. Prikl. Biokhim. Mikrobiol., 37:702-705. doi: 10.1023/A:1012307202011 Methanol institute (2018a) [Internet]. The Methanol Industry [cited 2018 Nov 27]. Available from: http://www.methanol.org/the-methanol-industry/

Methanol institute (2018b) [Internet]. Our members [cited 2018 Nov 27]. Available from: https://www.methanol.org/our-members/

Mustakhimov II, Reshetnikov AS, Glukhov AS, et al. (2009) Identification and characterization of EctR1, a new transcriptional regulator of the ectoine biosynthesis genes in the halotolerant methanotroph Methylomicrobium alcaliphilum 20Z. J. Bacteriol., 192(2):410-7.

Myung J, Flanagan JCA, Waymouth RM, et al. (2017) Expanding the range of polyhydroxyalkanoates 
synthesized by methanotrophic bacteria through the utilization of omega-hydroxyalkanoate cosubstrates. AMB Express, 7:118. doi: 10.1186/s13568-017-0417-y

Nguyen AD, Hwang IY, Lee OK, et al. (2018) Systematic metabolic engineering of

Methylomicrobium alcaliphilum 20Z for 2,3-butanediol production from methane. Metab. Eng., 47:323-333. doi: 10.1016/j.ymben.2018.04.010

Nwodo UU, Green E \& Okoh AI. (2012) Bacterial exopolysaccharides: Functionality and prospects. Int. J. Mol. Sci., 13:14002-14015.

Pastor JM, Salvador M, Argandoña M, et al. (2010) Ectoines in cell stress protection: Uses and biotechnological production. Biotechnol. Adv., 28:782-801. doi:

10.1016/j.biotechadv.2010.06.005

Patil KR, Rocha I, Förster J \& Nielsen J (2005) Evolutionary programming as a platform for in silico metabolic engineering. BMC Bioinformatics., 6:308. doi: 10.1186/1471-2105-6-308

Petersen LAH, Villadsen J, Jørgensen SB, et al. (2017) Mixing and mass transfer in a pilot scale Uloop bioreactor. Biotechnol. Bioeng., 114:344-354. doi: 10.1002/bit.26084

Pieja AJ, Morse MC \& Cal AJ (2017) Methane to bioproducts: the future of the bioeconomy? Curr. Opin. Chem. Biol., 41:123-131. doi: 10.1016/j.cbpa.2017.10.024

Pieja AJ, Sundstrom ER, Criddle CS (2011) Poly-3-hydroxybutyrate metabolism in the type II methanotroph Methylocystis parvus OBBP. Appl. Environ. Microbiol., 77(17):6012-6019. doi: 10.1128/AEM.00509-11.

Reshetnikov AS, Khmelenina VN \&Trotsenko YA. (2006) Characterization of the ectoine biosynthesis genes of haloalkalotolerant obligate methanotroph "Methylomicrobium alcaliphilum 20Z.” Arch. Microbiol., 184:286-297. doi: 10.1007/s00203-005-0042-z

Reshetnikov AS, Khmelenina VN, Mustakhimov II, et al. (2011) Genes and enzymes of Ectoine biosynthesis in halotolerant methanotrophs. Methods Enzymol., 495:15-30. doi: 10.1016/B9780-12-386905-0.00002-4

Ritala A, Häkkinen ST, Toivari M, et al. (2017) Single Cell Protein-State-of-the-Art, Industrial Landscape and Patents 2001-2016. Front. Microbiol., 8:2009.

Rostkowski KH, Pfluger AR \& Criddle CS (2013) Stoichiometry and kinetics of the PHB-producing 
type II methanotrophs Methylosinus trichosporium OB3b and Methylocystis parvus OBBP.

Bioresour. Technol., 132:71-77. doi: 10.1016/j.biortech.2012.12.129.

Sheets JP, Ge X, Li YF, Yu Z, et al. (2016). Biological conversion of biogas to methanol using methanotrophs isolated from solid-state anaerobic digestate. Bioresour. Technol., 201:50-57. doi:10.1016/j.biortech.2015.11.035

Simon R, Priefer U, \& Pühler, A. (1983) A Broad Host Range Mobilization System for In Vivo Genetic Engineering: Transposon Mutagenesis in Gram Negative Bacteria. Nature Biotechnol., 1:784-791. doi: org/10.1038/nbt1183-784

Stępniewska Z, Goraj W, Kuźniar A, et al. (2014) Biosynthesis of ectoine by the methanotrophic bacterial consortium isolated from Bogdanka coalmine (Poland). Appl. Biochem. Microbiol., 50:594-600. doi: 10.1134/S0003683814110039

Strong P, Laycock B, Mahamud S, et al. (2016a) The Opportunity for High-Performance Biomaterials from Methane. Microorganism., 4:100-111. doi: 10.3390/microorganisms4010011

Strong PJ, Kalyuzhnaya M, Silverman J, et al. (2016b) A methanotroph-based biorefinery : Potential scenarios for generating multiple products from a single fermentation. Bioresour. Technol., 215:314-323. doi: 10.1016/j.biortech.2016.04.099

Sugimori D, Takeguchi M, \& Okura I. (1995) Biocatalytic methanol production from methane with Methylosinus trichosporium OB3b: an approach to improve methanol accumulation. Biotechnol. Lett., 17(8), 783-784. doi:10.1007/BF00129004

Sundstrom ER \& Criddle CS. (2015) Optimization of Methanotrophic Growth and Production of Poly(3-Hydroxybutyrate) in a High-Throughput Microbioreactor System. Appl. Environ. Microbiol., 81(14):4767-4773.

Torre A, Metivier A, Chu F, et al. (2015) Genome-scale metabolic reconstructions and theoretical investigation of methane conversion in Methylomicrobium buryatense strain 5G(B1). Microb. Cell Fact., 14:188. doi: 10.1186/s12934-015-0377-3

Wendlandt KD, Jechorek M, Helm J, et al. (2001) Producing poly-3-hydroxybutyrate with a high molecular mass from methane. J. Biotechnol., 86:127-133. doi: 10.1016/S0168-1656(00)004089. 
Wilshusen JH, Hettiaratchi JP, De Visscher A, et al. (2004) Methane oxidation and formation of EPS in compost: Effect of oxygen concentration. Environ. Pollut., 129:305-314. doi: 10.1016/j.envpol.2003.10.015

Xin JY, Zhang YX, Zhang S, et al. (2007). Methanol production from $\mathrm{CO}_{2}$ by resting cells of the methanotrophic bacterium Methylosinus trichosporium IMV 3011. J. Basic Microbiol., 47(5), 426-435. doi:10.1002/jobm.200710313

Zhang T, Zhou J, Wang X, et al. (2016) Coupled effects of methane monooxygenase and nitrogen source on growth and poly- $\beta$-hydroxybutyrate (PHB) production of Methylosinus trichosporium OB3b. J. Environ. Sci., 52:49-57. doi:10.1016/j.jes.2016.03.001.

Zhen X, \& Wang Y (2015) An overview of methanol as an internal combustion engine fuel. Renew. sust. energ. rev., 52, 477-493. doi:10.1016/j.rser.2015.07.083 
Fig. 1.

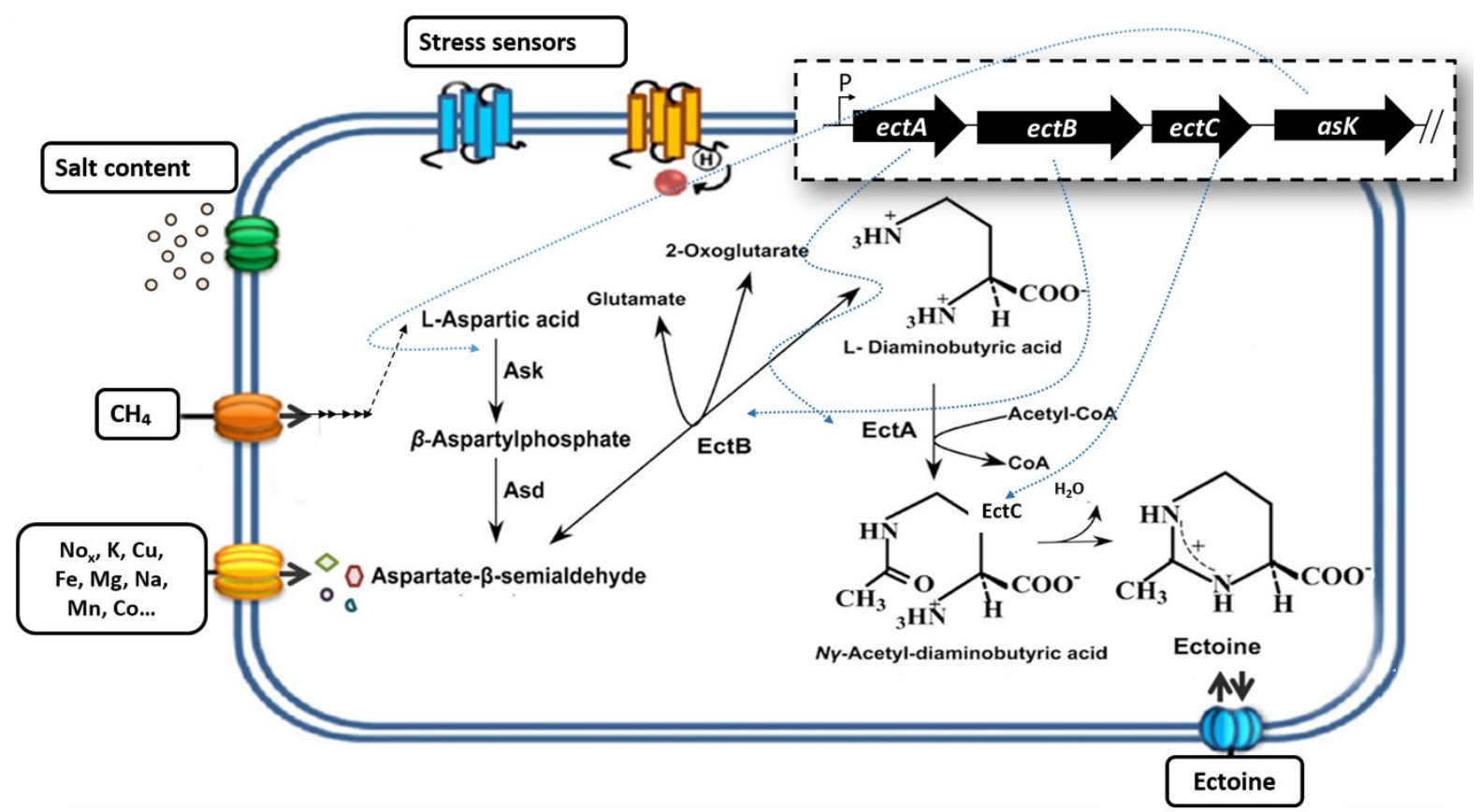

Fig. 1. Accumulation of ectoine in M. alcaliphilum 20Z, pathway for the synthesis of ectoine. Adapted from Pastor et al. (2010). ectA encodes for the protein DABA acetyltransferase (EctA), ectB for diaminobutyric acid (DABA) aminotransferase (EctB), ectC for ectoine synthase (EctC) and ask for aspartokinase (Ask). 
Fig. 2.

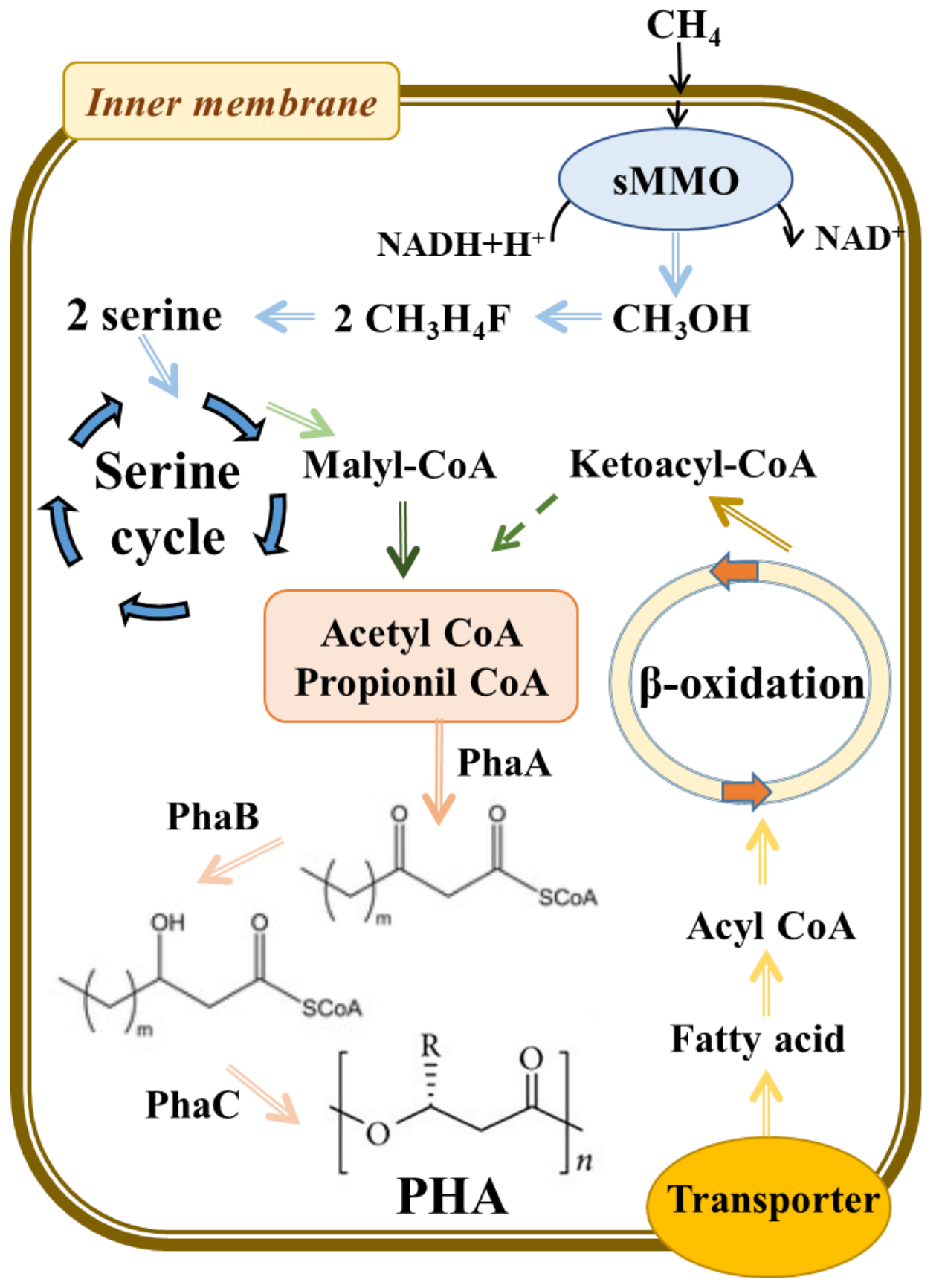

Fig. 2. An overview of the PHA production pathway in $\alpha$-proteobacter methanotrophs. 
Fig. 3.
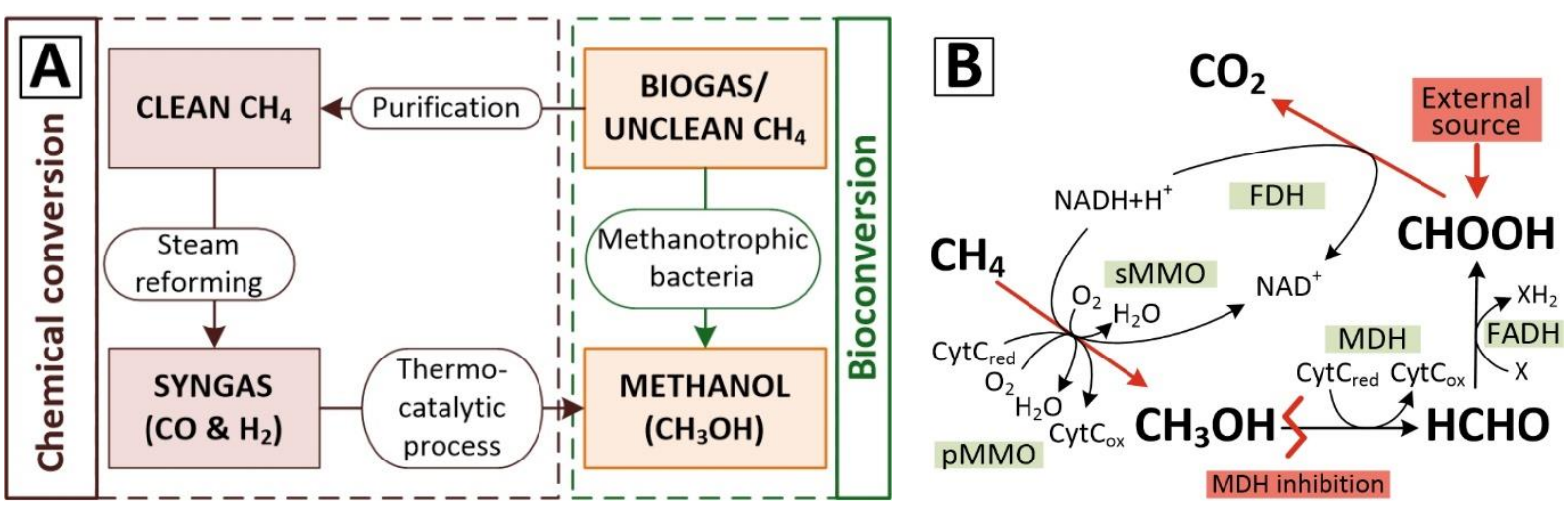

Fig. 3. Chemical and biological methane-to-methanol conversion (A) and methanol accumulation pathway by MDH inhibition and external addition of formate (B). Based on Ge et al., 2014 and Hanson \& Hanson, 1996. pMMO: particulate membrane-bound methane monooxygenase; sMMO: soluble cytoplasmic methane monooxygenase; MDH: methanol dehydrogenase; FADH: formaldehyde dehydrogenase; FDH: formate dehydrogenase 
Fig. 4

a

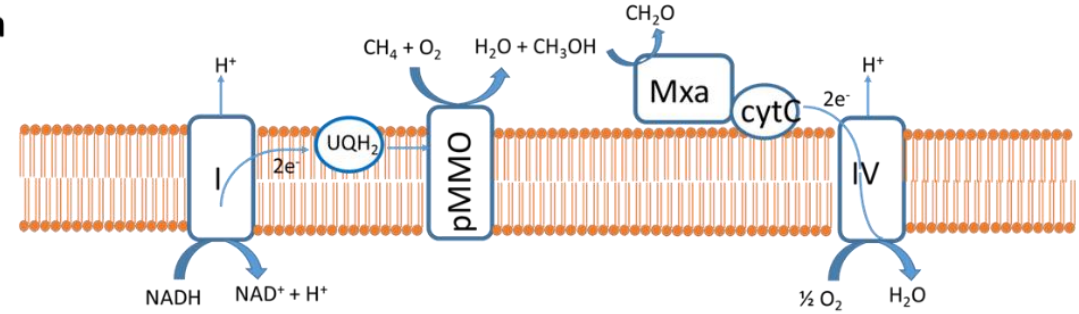

b

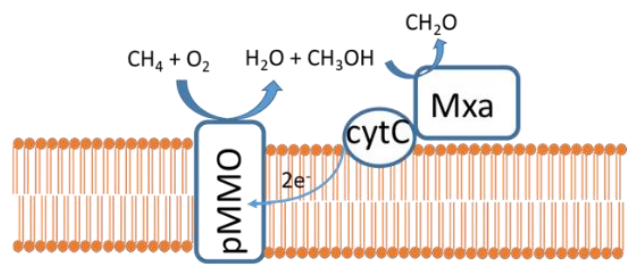

C

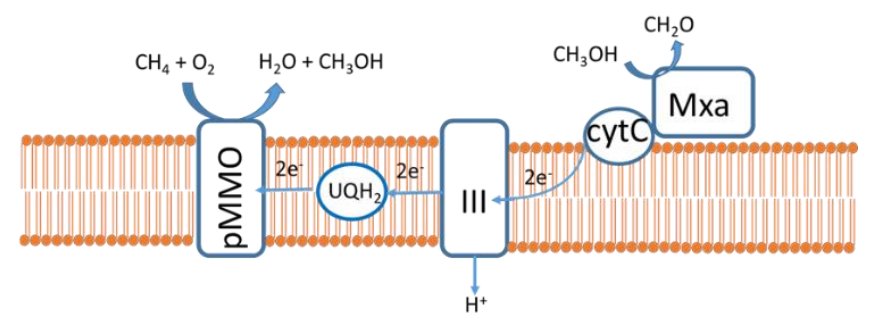

Fig. 4. Schematic of the three theories that account for the methane oxidation process: a) redoxarm, b) direct coupling c) uphill electron transfer. 


\begin{tabular}{|c|c|c|c|c|c|c|}
\hline Reference & Organism & $\begin{array}{c}\text { Type of } \\
\text { methanotroph }\end{array}$ & $\begin{array}{l}\text { Nutrient culture } \\
\text { conditions }\end{array}$ & $\begin{array}{l}\text { Operational } \\
\text { system }\end{array}$ & $\begin{array}{c}\left.\mathrm{CH}_{4}\right] \\
(\mathrm{v} / \mathrm{v} \\
\text { headspace }) \\
\end{array}$ & $\begin{array}{c}\text { Production } \\
\text { yield } \\
(\% w t) \\
\end{array}$ \\
\hline \multicolumn{7}{|c|}{ Ectoine production } \\
\hline $\begin{array}{l}\text { Khemelenina } \\
\text { et al. (2000) }\end{array}$ & $\begin{array}{c}\text { Methylomicrobium } \\
\text { alcaliphilum }\end{array}$ & $\begin{array}{c}\gamma- \\
\text { proteobacterial }\end{array}$ & $9 \% \mathrm{NaCl}$ & Serum bottles & 50 & 23 \\
\hline $\begin{array}{l}\text { Reshetnikov } \\
\text { et al. (2011) }\end{array}$ & $\begin{array}{c}\text { Methylobacter } \\
\text { marinus }\end{array}$ & $\begin{array}{c}\gamma- \\
\text { proteobacterial }\end{array}$ & $4 \% \mathrm{NaCl}$ & Serum bottles & 50 & 6 \\
\hline $\begin{array}{l}\text { Kalyuzhnaya } \\
\text { et al. (2008) }\end{array}$ & $\begin{array}{l}\text { Methylobacter } \\
\text { Kenyense }\end{array}$ & $\begin{array}{c}\gamma- \\
\text { proteobacterial }\end{array}$ & $5 \% \mathrm{NaCl}$ & Serum bottles & 50 & 7 \\
\hline $\begin{array}{l}\text { Kalyuzhnaya } \\
\text { et al. (2008) }\end{array}$ & $\begin{array}{c}\text { Methylomicrobium } \\
\text { butyarense }\end{array}$ & $\begin{array}{c}\gamma- \\
\text { proteobacterial }\end{array}$ & $5 \% \mathrm{NaCl}$ & Serum bottles & 50 & 6 \\
\hline $\begin{array}{c}\text { Cantera et al. } \\
\text { (2017a) }\end{array}$ & $\begin{array}{c}\text { Methylomicrobium } \\
\text { alcaliphilum }\end{array}$ & $\begin{array}{c}\gamma- \\
\text { proteobacterial } \\
\end{array}$ & $6 \% \mathrm{NaCl}$ & Continuous stirred tank reactor & 4 & 7 \\
\hline $\begin{array}{c}\text { Cantera et al. } \\
(2018 \mathrm{~b})\end{array}$ & $\begin{array}{c}\text { Methylomicrobium } \\
\text { alcaliphilum }\end{array}$ & $\begin{array}{c}\gamma- \\
\text { proteobacterial } \\
\end{array}$ & $6 \% \mathrm{NaCl}$ & Bubble column bioreactor & 4 & 10 \\
\hline \multicolumn{7}{|c|}{ PHA production } \\
\hline $\begin{array}{l}\text { Wendlandt } \\
\text { et al. (2001) }\end{array}$ & $\begin{array}{c}\text { Methylocystis sp. } \\
\text { GB } 25 \\
\end{array}$ & $\begin{array}{c}\alpha- \\
\text { proteobacterial } \\
\end{array}$ & $\mathrm{N} / \mathrm{P} / \mathrm{Mg}$ limitation & Stirred tank reactor & 20 & $51 / 4 / 28$ \\
\hline $\begin{array}{c}\text { Helm et al. } \\
\text { (2008) }\end{array}$ & $\begin{array}{l}\text { Methylocystis sp. } \\
\text { GB } 25 \text { (dominant in } \\
\text { a mixed culture) }\end{array}$ & $\begin{array}{c}\alpha- \\
\text { proteobacterial }\end{array}$ & $\mathrm{K} / \mathrm{S} / \mathrm{Fe}$ limitation & Stirred tank reactor & 25 & $33 / 32 / 10$ \\
\hline $\begin{array}{c}\text { Pieja et al. } \\
(2011)\end{array}$ & $\begin{array}{l}\text { Methylocystis } \\
\text { parvus OBBP }\end{array}$ & $\begin{array}{c}\alpha- \\
\text { proteobacterial }\end{array}$ & $\mathrm{N}$ limitation & Serum bottles & 50 & 50 \\
\hline $\begin{array}{l}\text { Rostkowski } \\
\text { et al. (2013) }\end{array}$ & $\begin{array}{c}\text { Methylosinus } \\
\text { trichosporium } \\
\text { OB3b/Methylocystis } \\
\text { parvus OBBP }\end{array}$ & $\begin{array}{c}\alpha- \\
\text { proteobacterial }\end{array}$ & $\mathrm{N}$ limitation & Serum bottles & 30 & $45 / 60$ \\
\hline $\begin{array}{l}\text { Sundstrom } \\
\text { \& Criddle } \\
(2015) \\
\end{array}$ & $\begin{array}{l}\text { Methylocystis } \\
\text { parvus OBBP }\end{array}$ & $\begin{array}{c}\alpha- \\
\text { proteobacterial }\end{array}$ & N limitation & 96-well microplates & 50 & 49 \\
\hline
\end{tabular}




\begin{tabular}{|c|c|c|c|c|c|c|}
\hline $\begin{array}{l}\text { Zhang et al. } \\
\text { (2016) }\end{array}$ & $\begin{array}{c}\text { Methylosinus } \\
\text { trichosporium } \\
\text { OB3b }\end{array}$ & $\begin{array}{c}\alpha- \\
\text { proteobacterial }\end{array}$ & N limitation & Serum bottles & 50 & $51 / 45 / 32$ \\
\hline $\begin{array}{l}\text { Myung et al. } \\
\text { (2016) }\end{array}$ & $\begin{array}{l}\text { Methylocystis } \\
\text { parvus OBBP }\end{array}$ & $\begin{array}{c}\alpha- \\
\text { proteobacterial }\end{array}$ & $\mathrm{N}$ limitation & Serum bottles & 5 & 60 \\
\hline $\begin{array}{l}\text { López et al. } \\
\text { (2018) }\end{array}$ & $\begin{array}{l}\text { Methylocystis } \\
\text { hirsuta }\end{array}$ & $\begin{array}{c}\alpha- \\
\text { proteobacterial }\end{array}$ & $N$ limitation & Serum bottles & 35 & 54 \\
\hline $\begin{array}{l}\text { García Pérez } \\
\text { et al.(2018) }\end{array}$ & $\begin{array}{l}\text { Methylocystis } \\
\text { hirsuta }\end{array}$ & $\begin{array}{c}\alpha- \\
\text { proteobacterial } \\
\end{array}$ & $\mathrm{N}$ limitation & $\begin{array}{c}\text { gas-recycling bubble column } \\
\text { bioreactor }\end{array}$ & 4 & 34 \\
\hline \multicolumn{7}{|c|}{ EPS production } \\
\hline $\begin{array}{l}\text { Malashenko } \\
\text { et al. (2001) }\end{array}$ & Methylococcus sp. & $\begin{array}{c}\gamma- \\
\text { proteobacterial }\end{array}$ & High $\left[\mathrm{PO}_{4}^{3-}\right]$ & Serum bottles & N.R & 38 \\
\hline $\begin{array}{l}\text { Malashenko } \\
\text { et al. (2001) }\end{array}$ & $\begin{array}{c}\text { Methylobacter } \\
\text { ucrainicus }\end{array}$ & $\begin{array}{c}\gamma- \\
\text { proteobacterial }\end{array}$ & High [PO43-] & Chemostat cultivation & 29 & 55 \\
\hline $\begin{array}{l}\text { Wilhushen et } \\
\text { al.(2004) }\end{array}$ & $\begin{array}{c}\text { Methanotrophic } \\
\text { consortium }\end{array}$ & $\begin{array}{c}\gamma- \\
\text { proteobacterial }\end{array}$ & & Fermenters & 38.5 & $\sim 60-80$ \\
\hline $\begin{array}{l}\text { Cantera et } \\
\text { al.(2018b) }\end{array}$ & $\begin{array}{l}\text { Methanotrophic } \\
\text { consortium }\end{array}$ & $\begin{array}{c}\gamma- \\
\text { proteobacterial }\end{array}$ & $\begin{array}{l}\text { High }[\mathrm{NaCl}] \text { and } \\
\text { alkalinity }\end{array}$ & Bubble column bioreactor & 4 & 107 \\
\hline $\begin{array}{l}\text { Cantera et } \\
\text { al.(2018b) }\end{array}$ & $\begin{array}{c}\text { Methylomicrobium } \\
\text { alcaliphilum }\end{array}$ & $\begin{array}{c}\gamma- \\
\text { proteobacterial } \\
\end{array}$ & $\begin{array}{l}\text { High }[\mathrm{NaCl}] \text { and } \\
\text { alkalinity } \\
\end{array}$ & Bubble column bioreactor & 4 & 79 \\
\hline \multicolumn{7}{|c|}{ Methanol production } \\
\hline $\begin{array}{l}\text { Sugimori et } \\
\text { al. (1995) }\end{array}$ & $\begin{array}{c}\text { Methylosinus } \\
\text { trichosporium } \\
\text { OB3b } \\
\end{array}$ & $\begin{array}{c}\alpha- \\
\text { proteobacterial }\end{array}$ & Cyclopropanol & Serum bottles & 25 & 71 \\
\hline $\begin{array}{l}\text { Duan et al. } \\
\quad(2011)\end{array}$ & $\begin{array}{c}\text { Methylosinus } \\
\text { trichosporium } \\
\text { OB3b }\end{array}$ & $\begin{array}{c}\alpha- \\
\text { proteobacterial }\end{array}$ & $\begin{array}{c}\text { High }\left[\mathrm{PO}_{4}{ }^{3-}\right] \text { and } \\
\mathrm{MgCl}_{2}\end{array}$ & Serum bottles & 50 & 64 \\
\hline $\begin{array}{l}\text { Han et al. } \\
\text { (2013) }\end{array}$ & $\begin{array}{l}\text { Methanotrophic } \\
\text { consortium }\end{array}$ & - & $\mathrm{NaCl}$ or $\mathrm{NH}_{4} \mathrm{Cl}$ & Serum bottles & 40 & 80 \\
\hline $\begin{array}{l}\text { Hwang et al. } \\
\text { (2015) }\end{array}$ & $\begin{array}{c}\text { Methylosinus } \\
\text { trichosporium } \\
\text { OB3b }\end{array}$ & $\begin{array}{c}\alpha- \\
\text { proteobacterial }\end{array}$ & $\begin{array}{c}\text { High }\left[\mathrm{PO}_{4}{ }^{3-}\right] \text { and } \\
\text { EDTA }\end{array}$ & Serum bottles & 30 & 73.8 \\
\hline
\end{tabular}



Click here to access/download Supplementary material JM\&B_cantera18_Cover.docx 